\title{
AN EVALUATION OF OSHAWA'S SUCCESS AS A CITY
}

by

Charlotte R. Balluch

BA, University of Ontario Institute of Technology, 2016

\author{
A Major Research Paper \\ presented to Ryerson University \\ In partial fulfillment of the requirements for the degree of \\ Master of Planning \\ in \\ Urban Development
}

Toronto, Ontario, Canada, 2019

(C) Charlotte Balluch 2019 


\section{Authors Declaration}

I hereby declare that I am the sole author of this MRP. This is a true copy of the MRP, including any required final revisions.

I authorize Ryerson University to lend this paper to other institutions or individuals for the purpose of scholarly research.

I further authorize Ryerson University to reproduce this MRP by photocopying or by other means, in total or in part, at the request of other institutions or individuals for the purpose of scholarly research. I understand that my MRP may be made electronically available to the public. 


\title{
AN EVALUATION OF OSHAWA'S SUCCESS AS A CITY
}

CCharlotte Balluch, 2019

Master of Planning

in

Urban Development

Ryerson University

\begin{abstract}
Understanding what makes a city successful will allow city planners to be intentional with their policy making, development, and overall goals. This research examined Nicholas Brooke's key components of successful cities to develop a framework for measuring success. Success factors that are supported by research include industrial, social and cultural diversity, skilled workforce, mobility, quality of life, culture of innovation, business-friendly, good governance, and a distinctive brand. Evaluation is an important part of learning, growth and future success. The City of Oshawa was evaluated on the basis of these eight factors. This paper has discovered that the City of Oshawa has a weakness in its distinctive branding, business-friendliness, and diversity. It is doing well in terms of having a skilled workforce, mobility, quality of life, and governance and it is excelling in its culture of innovation. Knowing these strengths and weaknesses gives planners and city staff the opportunity to work towards improvement of the struggling factors and leverage their strengths in order to make improvements.
\end{abstract}

Key words: City of Oshawa; success; economic growth; evaluation 


\section{Acknowledgments}

It is with much gratitude and appreciation that I thank Dr.F Mitchell Kosny for his guidance and support throughout the writing process. I would also like to thank my second reader, Michael Binetti for his valuable feedback on my work.

I would like to give special thanks to my family and especially my mom for always encouraging me to pursue higher education and achieve my goals.

Finally, I would like to express my appreciation to Scott for his patience and support over the past two years and during the writing of this MRP. 


\section{Table of Contents}

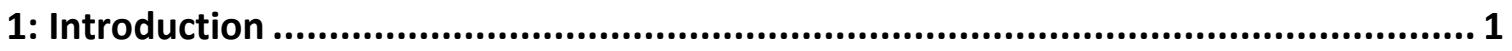

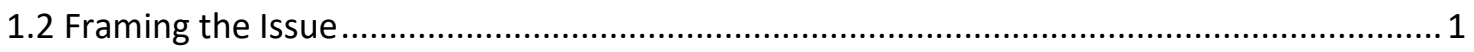

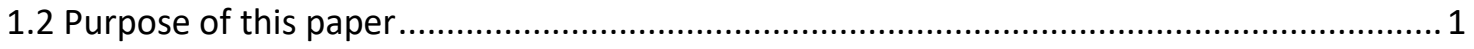

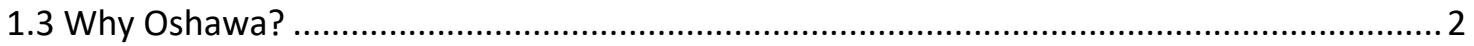

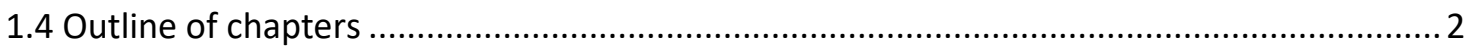

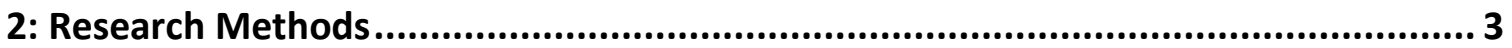

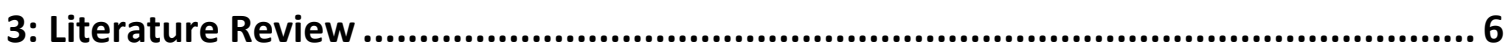

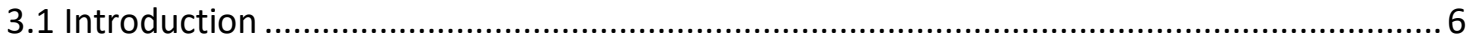

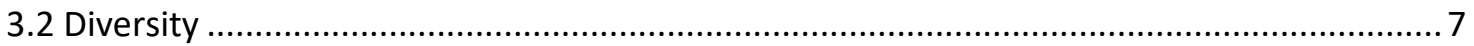

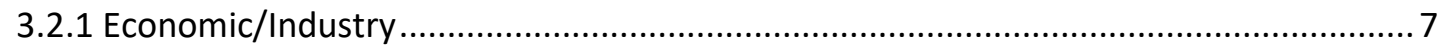

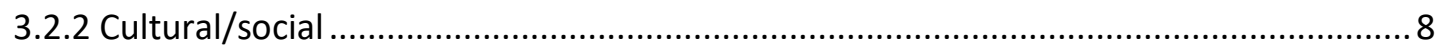

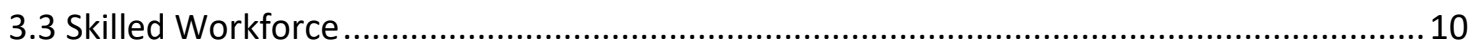

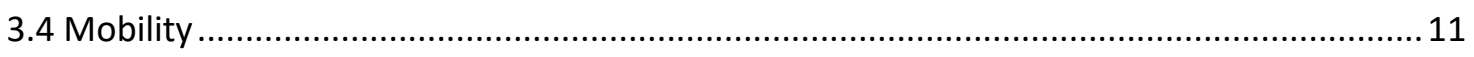

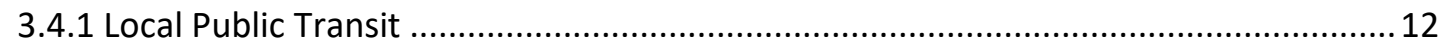

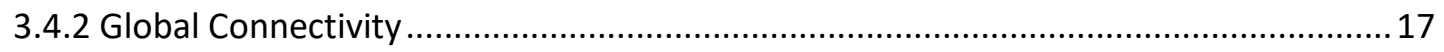

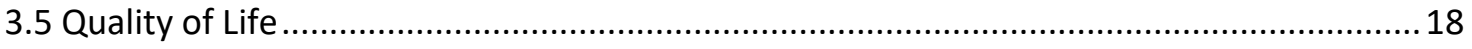

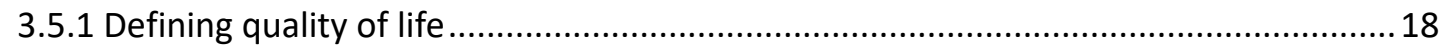

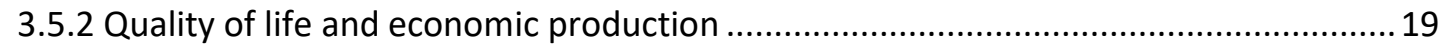

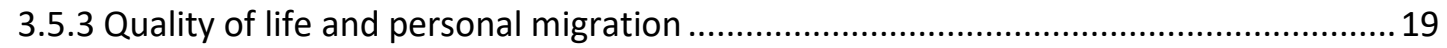

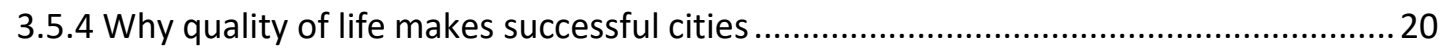

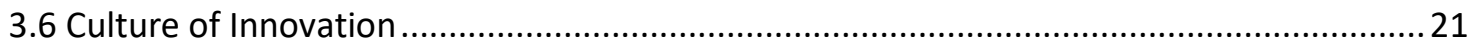

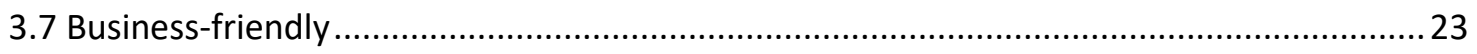

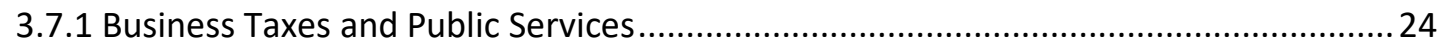

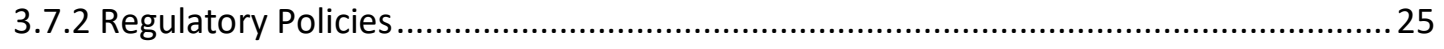

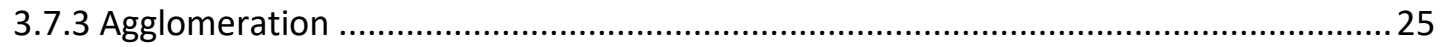

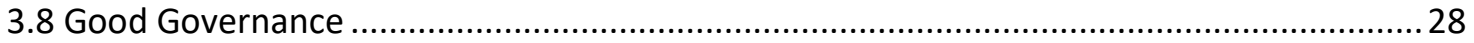

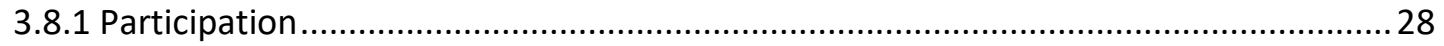

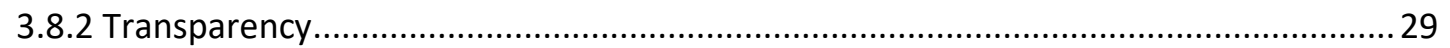

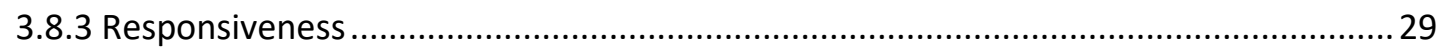

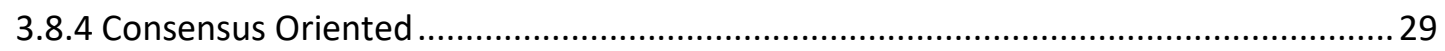

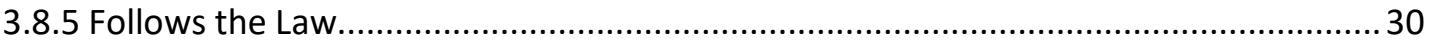




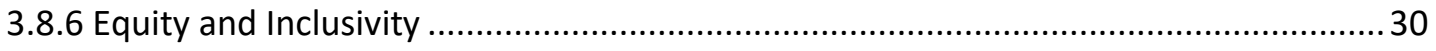

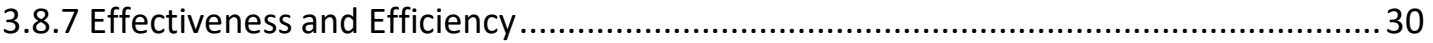

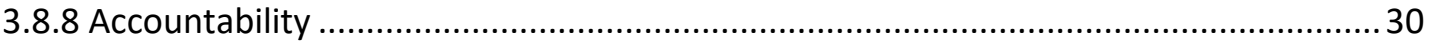

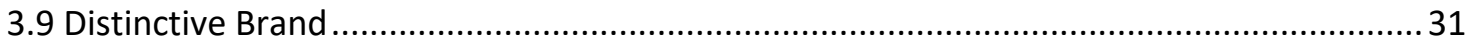

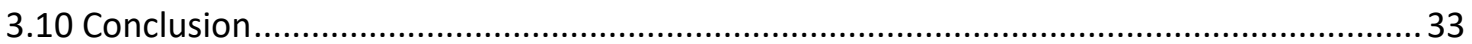

4: Findings and Evaluation of the City of Oshawa ............................................. 34

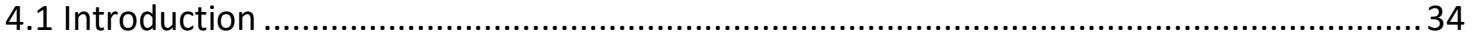

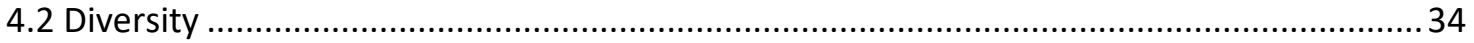

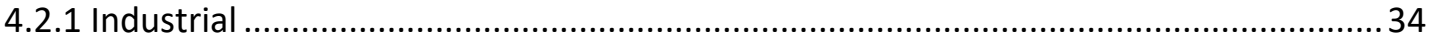

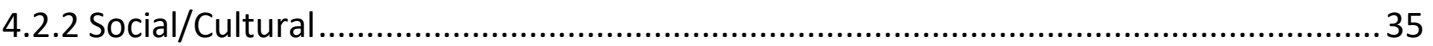

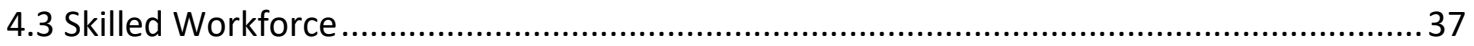

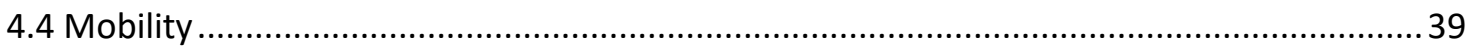

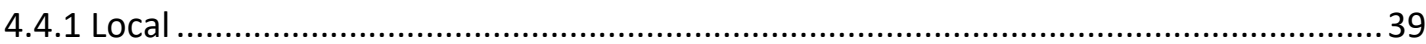

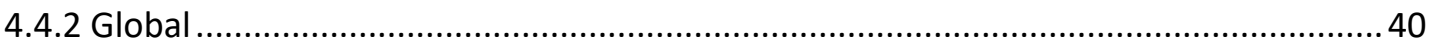

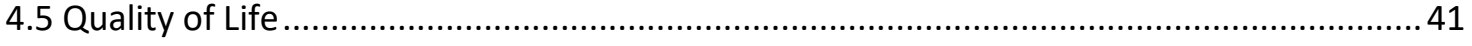

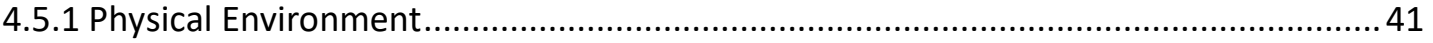

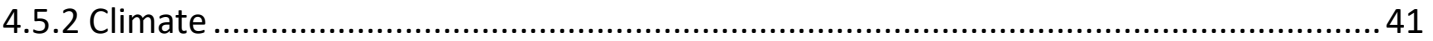

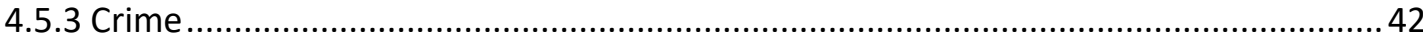

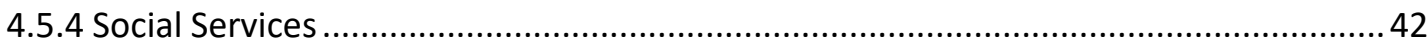

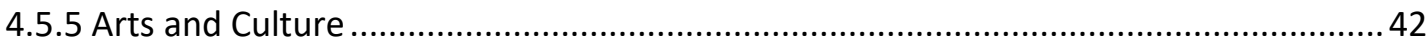

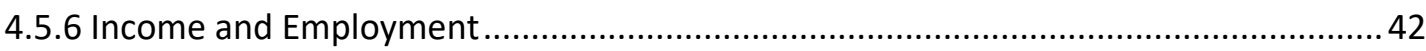

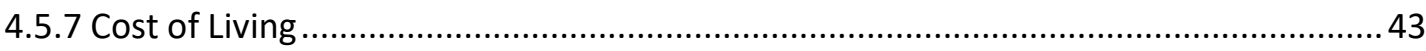

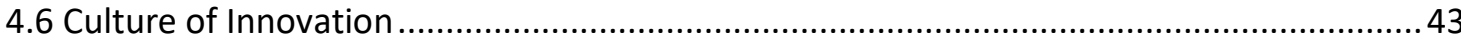

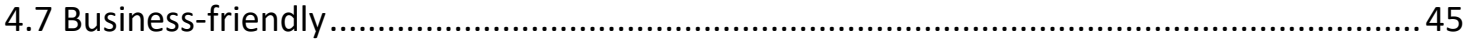

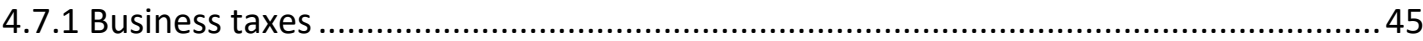

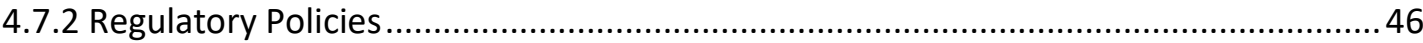

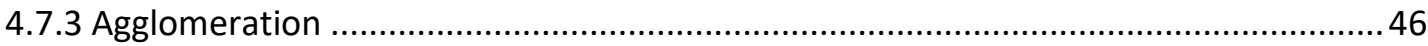

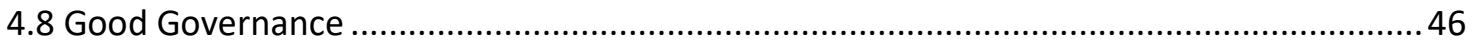

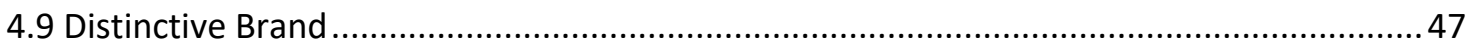

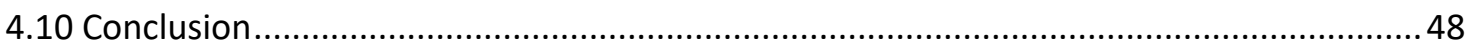

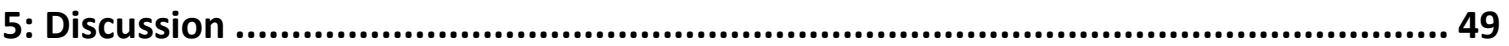

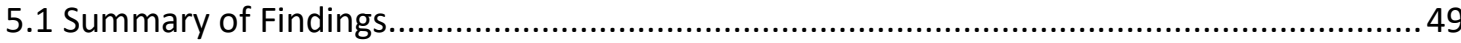

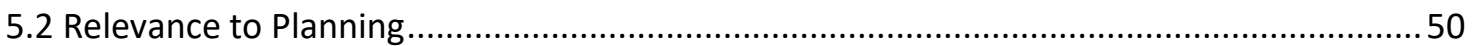




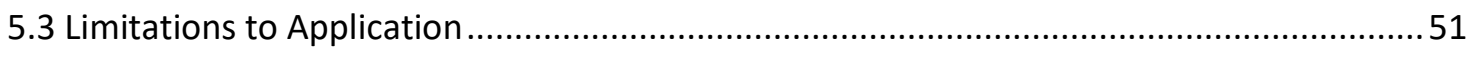

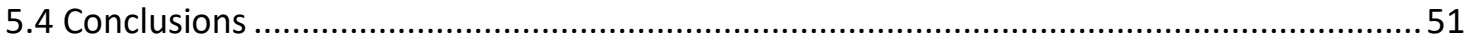




\section{1: Introduction}

\subsection{Framing the Issue}

According to the UN's World Cities data booklet (2016), an estimated 54.5\% of the world's population lived in cities in 2016 . This number is predicted to increase to $60 \%$ by the year 2030 . As people, businesses, and economic growth continue to concentrate in fewer places, small and midsized cities must work strategically and creatively to stay competitive and find their place in the world. Since over half of the world's population lives in cities, understanding the key factors that play a critical role of the long-term success of a city can help turn a city in decline into a thriving urban centre. Knowing the key factors to success can inform strategic planning intervention and the use of smart investments in the future of the city.

There are many factors involved in being a successful city. This research will use Nicholas Brooke's measures of success to assess the success of cities. Factors that are included in Brooke's model are economic, cultural, and social diversity, good governance, quality of life, a skilled workforce, connectivity within the city and to other cities, physical renewal, a culture of innovation, a businessfriendly culture and a distinctive brand (Brooke, 2004). Each of these factors contribute a piece to the overall success of any given city and will be explored in detail in the literature review of this major research paper.

\subsection{Purpose of this paper}

The purpose of this paper is two-fold. First, it will review Nicholas Brooke's key components and drivers that make a city successful. An extensive literature review on each factor will create an understanding of how and why each factor contributes to the success of a city. Based on these measures it can be determined in which factor any given city is successful and where it falls short.

This will be used to study the City of Oshawa and evaluate how well it fares under each factor of success. The City Oshawa is a midsized city that is located $60 \mathrm{~km}$ east of the City of Toronto. It is the largest municipality of Durham Region with a population of 161,000 (Statistics Canada, 2017). The City of Oshawa is a city that grew rapidly from 1953 due largely to its GM auto assembly lines (Statistics Canada, 2017). The city has potential to become a successful city as evaluated by Brooke's factors of success. This paper aims to acknowledge the steps in the right direction that Oshawa has made and also expose areas of improvement. 


\subsection{Why Oshawa?}

Toronto is growing rapidly in both population and economy. From 2011 to 2016, the population in the GTA grew by nearly 400,000 people (Statistics Canada, 2017). Furthermore, it saw an increase of over 140,000 jobs from 2011 to 2016 (Toronto Employment Survey, 2016). However, with this growth, Toronto has experienced significant growth challenges such as poverty and lack of affordability. While Toronto continues to be a forerunner of Canada's economy, the high cost of living and lack of affordable housing in Toronto is forcing economic activity and young talent into other areas. Mid-sized cities emerge as those with the most potential to offer an inclusive economic future that bridges the urbanrural divide (McFarland, 2017).

The City of Oshawa is a mid sized city at the border of the Greater Toronto Area. The reason the City of Oshawa has been chosen as the main focus of this paper is because it has the potential to become a more prominent regional player and take some of the growth pressure off the City of Toronto. It is home to several leading-edge institutions that are contributing to new and innovative research and academic programming. These include Durham College, University of Ontario Institute of Technology (UOIT), Trent University, Lakeridge Health Education and Research Network, Automotive Centre of Excellence (ACE) at UOIT, and Energy Systems and Nuclear Science Research Centre. It also has several connections to other parts of Ontario and Canada. Oshawa has a GO train station on the Lakeshore East line and a second station is proposed. It also has a VIA rail station connecting it to all of Canada. Moreover, the City of Oshawa is projected to have the highest GDP growth in Ontario at 2.4 percent and is projected to be among the top 5 in Canada. Since Oshawa's growth is new, it has a great opportunity to plan for growth. This research paper is an attempt to realize Oshawa's potential and guide growth in a positive way that will lead it towards planned success. This in turn will contribute to the development of a sustainable, thriving, and inclusive national economy.

\subsection{Outline of chapters}

This research paper will begin by outlining the methods for which the research and evaluation of Oshawa will be conducted. A literature review of each factor will then be completed to gain an understanding of each factor. The City of Oshawa will be evaluated based on the factors that were shown to contribute to the success of a city to gain an understanding of Oshawa as a whole. Oshawa will be judged and compared to Ontario averages to determine whether Oshawa is sufficient in this factor or needs improvement. Finally, a discussion about what the results mean for Oshawa and next steps and conclusions that can be made from the research. 


\section{2: Research Methods}

There are many factors involved in contributing to the success of a city. This research paper will focus on industrial, social, and cultural diversity, skilled workforce, mobility, quality of life, culture of innovation, business-friendly, good governance, distinctive brand, and urban renewal. In order to justify why each factor is used as a measure of success, research must be conducted on each factor individually. A literature review will be conducted surrounding the merits of each factor and how it independently contributes to the success of a city.

If the literature review reveals that a factor can be independently related to the success of a city, then it will be used as a part of the model of success that will be used later in the research paper to evaluate the City of Oshawa. If the literature is inconclusive or shows that any particular factor is not independently related to the success of a city, it must be removed from the model and will not be used to measure the success of Oshawa.

Once the factors of success have been validated by an extensive look at the surrounding literature, they can be applied to the City of Oshawa to examine how well the city is doing in terms of diversity, skilled workforce, mobility, quality of life, culture of innovation, business-friendliness, good governance, distinctive brand, and urban renewal. This research aims to discover where Oshawa is in regards to execution of the success factors explored earlier in the paper, as well as areas of strength or improvement.

The evaluation method for the way in which each factor is presented in the City of Oshawa varies between factors. Some factors such as diversity, skilled workforce and quality of life can be expressed quantitatively through census data, while others require a more qualitative approach to understand how that factor is expressed such as mobility, culture of innovation, business-friendly and distinctive brand. Each factor will be compared to a baseline of Ontario's average or standard.

Diversity will be evaluated by comparing Oshawa census data to Ontario census data. Characteristics that will be examined that make suggestions about the industrial, social, and cultural diversity of a population include occupation, industry, age, income, immigrant status, mother tongue, and ethnic origin.

Skilled workforce will be evaluated by examining opportunities to receive higher education such as examining the quality and quantity of post-secondary institutions in the city. It will also examine 
census data and compare to Ontario averages. The census characteristic that will be examined is the population's highest level of education completed.

Mobility will be examined by exploring the transit options that are available in Oshawa locally, as well as access to global mobility. Oshawa's population will be taken into consideration when examining mobility. The Growth Plan for the Greater Golden Horseshoe (2016) has guidelines for expected population density surrounding certain types of transit. Furthermore, other cities will be compared to get an understanding of the type of transit that is appropriate for the size of the population.

Quality of life will be measured with a mix of census data, crime statistics, employment ratings, and cost of living, each retrieved from their respective sources. The results from this information in Oshawa will also be compared to Ontario averages to gain an understanding of Oshawa's level of success in this factor.

Culture of innovation will be evaluated by examining how much opportunity there is in the City of Oshawa to learn, investigate and innovate. This understanding will come from the number and quality of post-secondary institutions as well as partnerships with businesses or programs offered in the city that are thought to foster a culture of innovation.

To evaluate the level of business friendliness in Oshawa, business taxes will be examined and compared to Ontario averages for business costs. It will also examine the potential for economy of agglomeration in the City of Oshawa compared to other cities in Ontario.

Good governance will be evaluated based on Oshawa's encouragement of participation, transparency in their processes, responsiveness to their citizens' needs, is consensus oriented, follows the law, strives for inclusivity, equitability, effectiveness, efficiency, and accountability. Planning legislation will be examined to understand the level of good governance that is required by law and then Oshawa will be evaluated on meeting those standards and whether they go above and beyond requirements.

Finally, the level of distinctive branding will be determined by examining the City of Oshawa's efforts to create a city brand through initiatives, events, plans, or other branding ventures.

After evaluating each factor, Oshawa will be given a grade either [A] excellent, [B] good, [C] fair, or [D] poor. Once each factor is graded, conclusions can be made on where Oshawa is succeeding or can 
be improved. A summary of findings will be provided as well as any conclusions that can be drawn from the research and results.

This method of research and evaluation is a pragmatic approach to evaluating the City of Oshawa. It is a means to examine Oshawa by isolating pieces of it in order to get an understanding of each segment of the city. Each segment of the city comes then together to create the larger picture. This will give a more enriched evaluation of Oshawa with an understanding of all of its moving parts than if it were to be evaluated as a whole. 


\section{3: Literature Review}

\subsection{Introduction}

This chapter will review Brooke's measures of a successful city. The nine factors are each a characteristic that a city might have that would contribute to the success of that city. They include having diversity, a skilled workforce, local and global mobility, high quality of life, a culture of innovation, business-friendliness, good governance and a distinctive brand. Each subsection will begin by describing one of Brooke's factors of success. Then, there will be a brief review of the literature focusing on how that specific factor leads to success of a city. The goal is to establish how each factor independently contributes to the success of a city supported by research findings.

Urban renewal is also one of Brooke's factors of success. Urban renewal can include physical renewal as well as social and cultural renewal and Brooke claims that it can bring a city national and international attention as well as generate civic pride. Contrary to Brooke's findings, researchers (Widner (1986), White (2016), Clarke \& Wise (2018), Onkar et al (2008)) have found mixed results in regards to the success of urban renewal. While some cities have found that urban renewal has allowed the city to redefine itself in a positive manner, other cities have found that urban renewal has caused more harm to communities than good. Due to the questionable results of urban renewal, it has become a contentious subject. Because of the mixed results urban renewal has had, it can be concluded that it is not an integral part of the success of cities. Cities can experience success without engaging in urban renewal projects. For that reason, it will not be used as a measure of success for the purpose of this major research paper.

The term "successful" is used often in this chapter and can be ambiguous. For the purpose of this research, the term success encompasses many different forms of success that a city can experience. Some forms of success include economic success, citizen happiness, and population growth.

Economic success comes from continued economic development. Economic development refers to increased productivity, business activity, employment, income, property values, and tax revenue (Litman, 2011). Some of Brooke's factors of success such as a culture of innovation, businessfriendliness, and skilled workforce, among others, contribute to economic success of a city.

Citizen happiness is another indicator that a city is successful as it means the city is functioning at a high level and is providing for the needs of the community. Finally, population growth is another form of success. Similar to the happiness of citizens, population growth indicates that a city is doing 
something right. Because of this, it is attractive to new comers and businesses which can also be linked to increased economic activity and economic success.

Economic success, citizen happiness, and population growth go hand-in-hand and often when one is present, so is another. A city can be successful in a number of ways. The research that follows aims to explore how each factor contributes to the success of a city.

\subsection{Diversity}

Economic, cultural, and social diversity brings vibrancy to a city. Cities that depend on one or few economic sectors are vulnerable during an economic downturn. Diversifying economic producers ensure that if one sector is failing, the others will still support the economic functions of the city. Cities with more cultural and ethnic diversity garner more creativity that inspire innovation which is also important to a city's success. A city that embraces diversity is more attractive to the skilled migrants that have been integral to the economic success of cities around the world for many generations (Brooke, 2004). Brooke explains that economic, cultural and social diversity are important in the success of cities. How each kind of diversity contributes to success will be explored individually to understand how diversity in all facets results in the success of a city.

\subsubsection{Economic/Industry}

Researchers and theorists have recognized the importance of economic diversity in the success of cities. A report written by Johnson (2008) states that what is most important for the success of a given city is having diversity of industry, trades, and crafts. Though Johnson represents relatively new research, this revelation is not a new.

Jane Jacobs uses similar arguments about importance of economic diversity and explaining the stimulation of innovation and economic growth. Jacobs (1969) believes that the most important transfer of knowledge happens between different industries, rather than within them. This interaction results in a variety and diversity of geographically close industries to promote innovation and growth. This theory predicts that industries that are located in cities with a diverse set of industries should grow faster (Jacobs, 1969).

A study conducted by Glaeser et al. (1992) examined the concentration and competition in 170 of the largest U.S. cities in 1992 to see whether having one type of industry in a city led to faster economic growth than having diversity in industry type. They found that industries grew slower where one industry type was overrepresented (Glaeser et al, 1992). Meaning if a city had less industry 
diversity, it grew less and if it was more diverse, it grew more. This is consistent with Jacobs theory. This research finds that more diversity in a city's industry results in faster growth which is an indication of success. But growth is not the only positive result of diversity in a city.

Research conducted by Malizia and Ke (1993) examined the relationship between economic diversity and stability of a city. In this research, stability is defined as the absence of variation in economic activity over time. It is also a reflection of success as it offers a sense a security, and predictability for members of the community who live and work there. Having a sense of stability in one's neighbourhood is a desirable characteristic of a city. What is found in this study and throughout the literature is that more industrially diverse areas should experience more stable economic growth and less unemployment than less diverse areas (Malizia \& Ke, 1993).

The reasoning behind the research is the idea that a diverse economy has many different industries who each experience fluctuations of different severity and timing. Thus, as one industry is in decline, another industry may be on the rise. Employment gains in some industries offset employment losses in others. As a result, unemployment is stabilized in the greater economy of the city (Malizia \& Ke, 1993). In their study of unemployment rates during the 1972-1988 period, they found that cities with more economic diversity experienced lower unemployment rates and less instability compared to less diverse cities. They argue that diversity is a basic stabilizer of metro economies and is an important factor influencing a cities performance (Malizia \& Ke, 1993).

The importance of economic diversity for the success of a city is apparent. It provides a buffer in case one industry experiences a decline. This improves the resiliency of a city during economic hardship. It also allows for the intermingling of ideas between industries which evidence has shown to accelerate economic growth and innovation. Economic diversity is not the only type of diversity that contributes to the success of cities. Cultural and social diversity also play an important role.

\subsubsection{Cultural/social}

People have been migrating from one country to another since the beginning of time. Immigration was and continues to be a large contributor of population growth in Canada. Though in recent decades a negative perspective of immigration has arisen. Qadeer (2016) explains this apprehension to welcome immigrants arising from the ideology of nationalism and the perception of national identity. However, having a community which accepts and includes immigrants has positive effects on the justice system, schools, and trade. 
In the early twentieth century, immigrants were mostly peasants or labourers or industrial workers (Qadeer, 2016). Today, immigration in North America is different. Immigrants tend to come with varying educational and professional backgrounds. This brings a steady stream of highly qualified professionals who seek work as professors, doctors, entrepreneurs, and investors (Qadeer, 2016). The result is the introduction of an ethnically and culturally diverse workforce in all types of industries. Furthermore, their unique training and backgrounds may transpire into a significant knowledge gain for the receiving countries, regions, and cities.

For example, approximately $52 \%$ of the start-ups in Silicon Valley, California were founded by immigrants. Two of these companies include Intel and Google (Qadeer, 2016). In 2006 foreign students made up $46-61 \%$ of the doctorate degrees in science, mathematics, and computer sciences in the GTA (Milroy \& Wallace, 2002). In Britain from 1992 to 2002, over half of the registered doctors were educated abroad (Qadeer, 2016). Canada sees similar findings. By 2000, Canada had attracted 2.7 million foreign graduates.

There is no doubt that these highly skilled individuals have made significant contributions to the economic growth of each of these countries. They increase supply of quality workers and labourers the workforce needs for economic growth. They also expand the demand side of economic activity.

Johnson (2008) argues that the presence of a diverse population creates a differentiated level of consumer demand. People with different occupations will have a need for different products or interest in different activities. People with a different social background may also have different interests. Moreover, a population with diverse wage ranges will have different tastes than others. This set of individual preferences, interests, and tastes stimulates the market and leads to a strong and successful economy.

Diversity is important for the success of cities in a number of ways. Industrial diversity not only provides resiliency, but it also fosters fast economic growth and intellectual sharing between industries. It can be concluded that economic diversity is important to city success. Cities also depend on social and cultural diversity. Immigrants plays a large role in this aspect not only to avoid shrinking of their population but for the valuable contributions they make in cities. Their unique backgrounds and education provide new insight and new perspectives that would be lost had there not been interaction between them and native born and trained professionals. All of these factors make up the larger picture of diversity and how it translates to success. 


\subsection{Skilled Workforce}

Businesses need skilled employees, and employers will go wherever these workers are located according to Brooke (2004). Cities that invest in education and training and develop close working relationships between their schools, universities and businesses can attract new employers through this kind of investment. The city also needs to create an environment that will attract skilled workers and foster a culture of innovation, research and development (Brooke, 2004).

According to Glaeser (2005), education may be the most effective predictor of growth. This has been displayed for more than a century as cities in both the United States and Great Britain with more educated residents have grown faster than comparable cities with less education levels.

Educated residents can be thought of as a form of human capital. Thereby, a city with more educated residents is better off and has more growth potential. Glaeser (2005) tested this hypothesis. He examined 238 metropolitan areas between 1980 and 2000. He found that the population of cities where less than 10 percent of residents held a bachelor's degrees in 1980 grew an average of 13 percent over the twenty-year period. Among cities where 25 percent of residents held a bachelor's degree, the cities saw an average growth of 45 percent (Glaeser, 2005). This study shows that cities that have residents with post-secondary education experience growth at a faster rate than cities within lower post-secondary education.

Researchers over the years have contemplated which factor is independent in the educationgrowth relationship. They contemplate whether highly skilled workers generate economic growth or if well-educated individuals choose to live in more dynamic growing cities. Glaeser aimed to put this question to rest. To do this, he used the number of colleges per capita located in metropolitan areas because they provide a measurement that predicts education levels but is stable enough not to be affected by year to year changes in growth. The results of the study indicated that cities with twice as many colleges but similar in all other regards were likely to experience 4 percent faster population growth per decade after 1970 (Glaeser, 2005). This study provides strong evidence that high skill level and education causes expedited growth, not vice versa.

Cities with more skilled residents not only grow faster, but they also tend to have higher wages than their less-educated counterparts. In metropolitan areas where the number of college graduates increased by 10 percent more than otherwise similar cities, family incomes also grew 10 percent faster (Glaeser, 2005). At first glance this may not be surprising, as college graduates tend to earn higher 
wages than those without post-secondary education. However, in cities with more college graduates, those with degrees are not the only ones experiencing income increases. In higher skilled cities, even unskilled workers seem to obtain higher wages (Glaeser, 2005). Economist Enrico Moretti found that a 1 percent increase in the college-educated population resulted in an increase of 0.6 to 1.6 percent increase in everybody's wages (Moretti, 2004). Skilled workers not only benefit themselves, but also benefit the city as a whole.

With a growing population and increased wages, the demand for housing in highly skilled cities will also grow resulting in increased housing prices. One theory that tries to explain housing competition in these cities hypothesizes that well-educated individuals favour stricter zoning and land-use regulations (Glaeser, 2005). In less skilled cities, developers respond to housing demands by building large amounts of new dwellings by building upward, or sprawling out. In skilled cities, planning constraints inhibit new construction so the growing demand for new housing teamed with restricted growth leads to fast-rising housing prices. Restrictive development policy coupled with increased demand in a growing city drives housing prices up.

Increased housing prices can be a valuable asset for cities and can contribute to its future success. An increase in tax revenue for the municipality through property taxes means the city has more ability to provide more high-quality services to its residents. This makes the city even more competitive and attractive to new residents and businesses.

To summarize, cities that have a skilled workforce can lead to the success of a city in more ways than one. It spurs faster population growth, brings higher wages to all workers, and results in higher housing costs, which brings more property taxes for the municipality. Therefore, the benefits of having a skilled workforce is a key factor to the success of a city.

\subsection{Mobility}

Mobility within the city as well as to the broader region, province, or country are crucial (Brooke, 2004). A good airport and international rail links allow a city to make the leap to world class prominence. Likewise, good internal connections with a foundation of adequately funded public transit provide the essential infrastructure for the movement of people, goods and services (Brooke, 2004). Beyond simply the movement of people, goods and services, adequate public transit provides a host of social and economic benefits to a city, each of which play a role in the success of that city. 


\subsubsection{Local Public Transit}

Local public transportation influences communities and those living in them by supporting economic development, promoting sustainable lifestyles, and providing a higher quality of life. Everybody benefits from public transit. Individuals, families, and businesses all have something to gain when adequate public transit is made a priority in their city. For many years, planners have found that public transit is a key to the success of a city. The list of benefits of high-quality mass transit is vast. There are mobility benefits, efficiency benefits, land use impacts, economic development benefits, and environmental benefits. Each of these categories have large amounts of data explaining how transit can positively affect aspects of a city.

\subsubsection{1 mobility benefits}

Mobility benefits are derived from personal travel that would otherwise not occur. For example, trips that are taken by people who are transportation disadvantaged, in that they cannot drive or do not have access to a car due to physical, economic, or social constraints (Litman, 2011). In most communities, public transit may make up a relatively small portion of trips, however it is of high value to users and society in general. Transit provides basic mobility for everybody and is important in enabling people to reach important activities such as medical services, education, employment, and entertainment (Litman, 2011). Some mobility benefits exhibited by increased transit availability and use include user benefits, public services support, and equity benefits, each important reasons to prioritize quality transit service.

Local public transit benefits users by increasing access to services and activities. Through transit, people who are unable to drive or do not have access to a car can reach medical services, schooling, employment, social recreational activities, and financial savings by having a wider range of stores available to them (Litman, 2011). By improving access to education and employment, transit can have a direct impact on people's economic opportunities.

In a study conducted by Crain \& Associates (1999), many transit commuters reported that were it not for transit, they would be unable to continue working at their current place of employment. Similarly, many students depend on public transit to attend school or college, so a lack of transit would result in a loss of potential education and skilled residents, which is important for the success of cities, as discussed earlier in this chapter. 
Transit also helps achieve fairness and equity within a city. Adequate transit increases economic and social opportunities for people who are economically, physically, and socially disadvantaged (Litman, 2011). This helps achieve equity in a city by helping disadvantaged people access public services, education, and employment opportunities that may have otherwise been unattainable without access to a vehicle.

\subsubsection{2 efficiency benefits}

Efficiency benefits consist of cost savings and other benefits that arise when transit substitutes for single occupancy car travel (Litman, 2011). These include vehicle and parking costs savings, congestion reduction, health and safety improvements, and emissions reductions. Each of these benefits can act as a cost-effective way to reduce traffic congestion and parking problems that are particularly problematic in major commercial and employment centres found in downtowns. These benefits are heightened if transit improvements and incentives to use transit are designed to attract riders who would otherwise be driving (Litman, 2011).

When a person shifts from single car ridership to transit ridership, they experience large cost savings. At minimum, moving from driving to transit saves on fuel, oil, and insurance. Depending on the driver's situation they could also save on car payments, depreciation of their car, and parking costs. Conservatively, Litman (2011) estimates drivers could save 20 to 25 cents USD per mile reduced. That is equal to 43 to 58 cents CAD per kilometer reduced. Savings could be even greater if using transit avoids road tolls or parking fees.

Another efficiency benefit to transit is the reduced traffic congestion that occurs as a result of less cars being on the road. Traffic congestion consists of delays, stress, increased vehicle operating costs, and pollution caused by cars reaching or exceeding road capacity (Litman, 2011).

Once roads reach capacity, small traffic reductions can make a significant improvement to congestion problems. In fact, reducing traffic by only 5 percent has been found to reduce delays by 20 percent or more (Litman, 2011). Another study revealed that as a city's rail transit mileage expands, traffic congestion often declines (Caselazo \& Garrett, 2004). Lastly, a study examining the introduction of the San Fernando Valley Orange Line busway in 2005 found that the introduction of this new transit resulted in less congestion. Commuters in the area experienced a reduction of time spent stuck in congestions of 14 percent (Liu, 2005). 
The reduction of cars on the road not only benefits those who are taking transit, but it also benefits those who still need to drive like truck drivers or people who drive for work. Clearing the way for those people will result in increased productivity which is good for a city's economy.

A city that sees a shift to transit will also work to reduce parking costs. This is because reduced vehicle ownership reduces parking demand which can either reduce the price of parking or result in underutilized lots (Liman, 2011). This benefit is multifaceted because it benefits users as cost saving, it benefits those who continue to drive since there will be less parking congestion, and may also benefit businesses in the future because they will not need to subsidize employee parking.

New development might also benefit if parking minimums decrease due to underutilization, resulting in large cost savings. This also benefits the city as less land is required for parking facilities, as it allows more clustered infill and development in a smaller land area. Ultimately, many people benefit from the reduction of parking demand and requirement.

Increased use of transit can also have a positive affect on the safety of a city as well as the health of its residents. Research has shown that transit passengers have about one-tenth of the fatality rate of car drivers or passengers. (Litman, 2011). Furthermore, transit users made up less than half of the total deaths per-passenger mile as automobile travel.

Not only is transit travel safer for passengers, increased transit-oriented development could form the framework for accessible and pedestrian friendly land use which tends to further increase road safety. Research has found that residents of transit-oriented neighbourhoods with high transit ridership rates have a significantly lower per capita traffic fatality rates than residents of auto-dependant neighbourhoods (Litman, 2011).

Increased transit is also beneficial to residents' health. Experts believe that increasing walking and cycling activity is one of the most practical ways to increase public health (Litman, 2011). Most transit trips require at least some walking or cycling to get to and from the transit stop or station, so transit inherently increases physical activity.

Besser and Dannenberd (2005) found that public transit users walk an average of three times as much as people who rely on driving. Another study had commuters wear pedometers for a week to measure how many steps were walked per day for drivers and transit users. They found that train commuters walked an average of 30 percent more steps per day, walked at least 10 minutes as part of their travel more often than drivers, and were four times more likely to walk the recommended 10,000 
steps per day than car commuters (Wener \& Evans, 2007). This research emphasizes the need to encourage transit, reduce driving, and create transit-oriented development in an effort to facilitate increased walking and cycling and further increase fitness and health of residents.

Health and safety are important for a city and can lead to increased efficiency. Less road accidents by reducing road use can save a city money by having to send fewer emergency vehicles and less road monitoring. Additionally, having healthier residents means the city will spend less on healthcare or other rehabilitative services. Both of these factors contribute to a more efficient city. Health, safety, and efficiency are important to the success of a city and should therefore be encouraged.

In addition to health and safety efficiency benefits, transit can provide energy conservation and emission reduction benefits. When transit is designed for efficiency such as on major urban corridors, it can provide substantial energy conservation and emission reduction benefits (Litman, 2011). Urban transit travel is estimated to consume about half of the energy and produces only about 5 percent as much $\mathrm{CO}$ and $\mathrm{VOC}$, and 50 percent of the $\mathrm{CO}^{2}$ and NOx emissions per passenger-mile as an average car (Shapiro et at., 2002). Furthermore, reduced traffic congestion caused by increased transit use as well as more efficient land use patterns reduces up to 37 million metric tons of $\mathrm{CO}^{2}$ (ICF, 2008). Better air quality in a city is attractive to people and businesses and also improves the health of residents.

Adequate transit options are vital in ensuring a city will function efficiently. Transit offers vehicle and parking cost savings to riders, reduces congestion, increases the health and safety of the riders and the public, as well as reduces emissions that are harmful to the environment.

\subsubsection{3 land use impacts}

Transit can help achieve many land use planning objectives which can lead to the success of a city. Ways in which transit can help is by reducing the amount of land required to roads and parking facilities, and providing the framework for more compact development that is serviced by transit (Litman, 2011).

Smart city planning that includes efficient and accessible land use patterns often hinge on quality public transit. Transit is particularly important in the successful planning of major commercial centres. For example, Toronto's plans to redevelop the Unilever site is centred on having quality transit first in order to ensure the success of the proposed major employment centre. Transit oriented development can provide economic benefits by improving accessibility, reducing transport costs, and facilitating agglomeration economies (Litman, 2011). 
A study found that increased density such as that found in transit-oriented development is associated with increases in region-wide productivity increases (Haughwout, 2000). Another study found that metropolitan region labour productivity declines as populations become more dispersed. Likewise, productivity generally increased in more dense cities that had multiple business districts. It follows that adequate transit enhanced by transit-oriented development around stations tend to support economic development by encouraging efficient land use development patterns.

Transit users are not the only ones who benefit from this type of development. Every member of the public benefits from a more human-scale development that occurs when transit is favoured over automobiles.

\subsubsection{4 economic development impacts}

Increased availability and use of transit can result in significant economic development impacts. These could include the creation of new jobs, resident savings on transportation, productivity gains, land use efficiencies, and transit system improvements that can create a positive feedback loop where improved transit results in more opportunity to improve transit.

Transit requires people to drive the buses and trains, as well as toll collection and maintenance on rails and roads. Because of this, transit expenditures tend to provide more jobs and local business activity than most other transportation investments (Litman, 2011). For instance, one million dollars spent on public transit has been shown to generate 30-60 jobs on average (APTA, 2003). That same investment on a typical set of road and bridge projects would see 19 percent less job creation.

In addition to the creation of jobs, transit services can increase the productivity of existing businesses. Transit reduces traffic congestion which allow for more timely delivery of products, as well as reducing parking facility costs, increasing land use efficiencies, and by supporting economies of agglomeration. A study by Aschauer and Campbell (1991) found that transit investments provide more than twice the return in worker productivity than the same investment in highway improvements. The creation of jobs and efficient use of space is important for a city's economy and it allows a city to be more productive and be a more attractive place to live and do business.

Another benefit for residents and workers in cities with higher quality transit systems is that they tend to spend less of their yearly income on transportation. Residents of cities with extensive quality rail transit systems spend an average of 12 percent of their yearly income on transportation, compared to 14.9 percent in cities that lack rail systems (Litman, 2011). These household savings alone 
could draw more people to the city which demonstrates the importance of transit for a city's competitiveness.

Transit investment and improvement increases the system's efficiency. When a city prioritizes transit, it can lead to the systems increased operating speed, improve quality, and reduce operating costs (Litman, 2011). The cost to use transit is typically fixed, and additional users do not affect operating costs, especially if the transit mode is below capacity. Thus, increased ridership increases revenue from the service. As per-capita ridership increases, the system can expand by increasing service frequency, coverage, and operating hours. Increased quality service will become attractive for people and businesses to locate near which will result in more ridership and further improvements. Strategies that increase transit ridership can be the catalyst for service expansion and the degree of benefits experienced by a city will continue to grow.

It is clear that local transit options present many benefits to a city. Transit should be at the core of development in order to create a city that is competitive and successful. High quality transit results in a city that is equitable, efficient, and productive. All three of these things are important for people and businesses to choose to live and work in a city. Each are important for a city's success.

\subsubsection{Global Connectivity}

Global connectivity typically refers to the ability to connect to the rest of the world in a fast and efficient manner, namely, air travel. Airplanes are the fastest way to travel long distances. For example, one could fly anywhere in the world in less than a day where travel by train, boat, and car would take many days or weeks.

Richard Florida (2018) examined multiple studies to determine how airports drive economic growth. Florida and colleagues found that airports help to propel regional economic prosperity. They also found that airports have a more significant impact on regional growth than the introduction of hightech industry, and about the same impact as having a highly skilled workforce (Florida, 2018).

As discussed earlier in this chapter, having a culture of innovation that often brings high-tech businesses as well as having a highly skilled workforce among the city's population are both important factors of success. The results of this study show that being globally connected through an airport is just as important for economic growth, and therefore success, of a city.

Florida also speaks of another study which compared United States domestic air traffic before and after the deregulation of the airline industry. It found that increased air traffic led to an increase in 
population, income and employment in cities (Florida, 2018). Increases in population, income and employment are each indicators of success in a city. Thus, having an airport in the city or increasing access to an airport through transit is a benefit to the city and will contribute to its economic success.

Overall, having transit options within the city is found to provide a large number of benefits to the city and those who work and conduct business there. Benefits range from mobility and social benefits, to efficiency and economic benefits, each playing a role in the success of the city. Airport access has proven to provide additional benefits to the city such as population and economic growth. Mobility within the city and to the rest of the world is proven to be a key to success.

\subsection{Quality of Life}

Creative, talented people whom cities need have many choices of where they choose to live, work and play. Brooke claims there is evidence that suggest that people are attracted to cities that offer more than financial rewards, but also a quality of life they aspire to have (Brooke, 2004). While excellent employment prospects may be a strong draw to a city, other aspects such as social services and cultural institutions are also important considerations people make.

\subsubsection{Defining quality of life}

The problem with some research on quality of life is that they provide no definition, but simply accept the term blindly. The way that quality of life should be conceived should reflect the concerns of economic producers, the public, and potential migrants.

Sack (1988) suggests that a place is often thought of as a unique set of attributes at a unique location. With such a view, one can determine that quality of life should be based on a set of attributes of places which provide benefits to living or working there.

Researchers have used various attributes to measure quality of life such as environment/pollution, atmosphere/peace and quiet, climate, lifestyle opportunities, employment, retirement, housing costs and access, health care, crime/public safety, transport, traffic, education, recreation, economy/business, arts and cultural diversity, taxes, commercial space, food costs, political involvement, and wages (Rogerson, 1999). While this list offers specific elements that are each involved in defining quality of life, the common themes throughout include factors surrounding the physical environment, climate, pollution, crime, and social services in the form of health and education. 
Rogerson (1999) asserts that the main goal of quality of life is to commodify the city in an attempt to lure capital though economic production or by attracting talent. This means that when a city improves quality of life for its citizens, that city becomes more competitive and thereby, successful.

\subsubsection{Quality of life and economic production}

Within the context of successful cities, quality of life has been adopted as one of the many ways a city can secure growth and development through the attraction and retention of economic production (Johnson, 1999). Johnson argues that quality of life is a factor underpinning location. It draws from the fact that many new businesses choose to locate in amenity rich areas and are moving away from the older declining industrial centres.

It can also be argued that new trends in location factors such as better communications and technological flexibility, office costs, land value, and labour cost are influencing the spatial patterns of new economic activity (Johnson, 1999). However, growth industries seek quality of life in their own right. Research suggests that quality of life can be a significant cause for considering one location over another in the decision-making process (Johnson, 1999). One study conducted by Hart et al. (1988), even found that the single most important factors to a firm's location in a country appears to be quality of life related attributes such as the quality of the local environment, proximity to markets and residents, and the area's growth potential. They also acknowledged that the quality of life factors that were important to the decision varied depending on the type of industry but that quality of life in general consistently remained an important element in business location.

While new businesses may not outwardly express that quality of life is an important factor for their decision making per se, they often consider things like cost of living, public transit, crime, schools, and environmental quality important which can ultimately be categorized as quality of life factors anyway. Locating a business in a city is only half of the equation. Businesses need people to work and operate them. Quality of life plays a role in attracting people to areas which further leads to the success of a city's growth and competitiveness.

\subsubsection{Quality of life and personal migration}

Quality of life has been linked to city competitiveness through the attraction of capital via personal migration. In this case the focus of quality of life is targeted towards personal needs and values (Johnson, 1999). The competitiveness of the city is driven by consumer power as people who have money to relocate to a more desirable city will do so. 
Johnson (1999) argues that a major compelling force for selective migration by professionals and higher income families from cities to smaller town and villages, largely for quality of like and environmental reasons. Johnson's paper was written in 1999 and at that time, the suburbs were more attractive because they were separated from industry. However today there is a trend of people moving back to city centres likely due to the fact that harmful industries that produce noxious smell, noise, and air pollution have moved out of the city cores and these areas are rich with amenities which provide a higher quality of life than the suburbs do.

Williams and Jobse (1990) analyzed migration patterns across the US in the 1990's and found that quality of life factors rather than economic factors were better at explaining migration from certain areas to others. This analysis points to the importance for cities to provide a high quality of life as this is what attracts new people and keeps current residents situated.

The results found in these studies do not only apply to citizens, but can also be applied to international immigrants. A survey conducted by Findlay and Rogerson (1993) asked new migrants about their motivations for moving. They established that quality of life reasons were important to more than $70 \%$ of the migrants interviewed. These factors were found to be more important than employment opportunities, living costs, or family ties (Findley \& Rogerson, 1993). Findley and Rogerson acknowledge that is can be difficult to pinpoint exact reasons for moving and mention that this is a weakness of the study. However, it is a common notion that immigrant parents often talk about moving to the US or Canada in hopes for a better life for their children. These people sometimes come with very little money in their pockets and enter the country without having secured employment. The evidence suggest that quality of life is a significant draw for people locally and internationally.

\subsubsection{Why quality of life makes successful cities}

What is generally accepted in this body of research is that the municipal government has become increasingly tasked with the creation of urban conditions that are attractive enough to lure potential capital into the area (Johnson, 1999). The main contribution that quality of life brings to a city is the ability to capture capital through in the idea of place making and marketing. The city attempts to create a distinctive image of an atmosphere which acts to attract business and people. There are many examples of how quality of life ratings are used as part of place promotion to attract this capital.

Each year a number of quality of life indexes rank countries or cities on quality of life. For example, the Mercer Quality of Life Survey, The Where to be Born Index, CNBC World Report on the 10 
Countries with the Best Quality of Life and so on. In 2018 Vienna has found itself at the top of the list for the ninth consecutive year (Mercer, 2018). Quality of life comparisons allow cities to raise their profile in the national and international economic view. It not only attracts the business community, but also tourists and potential residents. Some cities use an increased quality of life rating to challenge the negative perceptions people may have about the city such as being an area of industrial decline or unsafe.

It can be concluded that a city that provides a higher quality of life or the perception of high quality of life is exceptionally attractive for potential businesses which can leads to substantial economic growth. It also works to attract potential new comers to the area broadening the population. The growth of population and businesses in the city contributes to higher economic production which in turn increases the city's competitiveness or economic success. This determines that quality of life is an important factor to a city's success.

\subsection{Culture of Innovation}

Innovation is defined by Brookes as "the introduction of new techniques and processes" (Brooke, 2004). He explains that innovation is the key to creating knowledge-based industries that spawn high standards of living. Innovation depends on a strong base of research and the creation of public sector and private sector networks that work together to generate and share knowledge (Brooke, 2004).

Innovation comes in many forms such as new or significantly improved products, processes, marketing techniques, business practices, and workplace organization. Innovation does not have to be a radically new idea. While radical innovation provokes the largest and most immediate societal impact, minor shifts in practice, technique, or processes may be more palatable for employees, employers and the public while making positive incremental change. Small changes are not to be overlooked as many minor adjustments over time can lead to significant city-wide progress.

Research conducted by Johnson (2008) studied the role of innovation in cities, how cities are drivers of innovation, and why innovation is largely found in cities. Johnson points out that the reasons innovation is often found in cities, given by scholars such as Botero, Serra, and Jacobs rely on supply side arguments. They say the conditions for production and growth are better in cities than rural areas because capital and labour are more available, abundant, efficient, and complementary (Johnson, 2008). 
Additionally, cities tend to be more diversified in production structure and this supports the weaving of ideas and techniques which is where innovation is born.

Demand side factors are also important. These centre on the presence of a diverse population that include people of different values, occupations, social backgrounds, and socioeconomic status. Each of these groups having different interests and tastes and create a differentiated level of consumer demand (Johnson, 2008). Diversity and the individuality of members of the public form cities that are complex and often disordered places. Conflicting interests present problems which involve private participants and public authorities. Where there is conflict, there is opportunity to find a solution. Innovation often stems from seeing a problem, and using creativity and innovation to solve it.

It is clear why innovation is found in cities but how does innovation translate to success? As discussed, cities are problem-rich. Large groups of people living and working in an area puts strain on natural resources and energy. Increased congestion puts strain on local streets and transport systems (Johnson, 2008). City development can go through periods of innovation by recognizing these long-term problems, developing solutions for them, and by having an enhanced acceptance of change (Johnson,2008). Selecting and implementing solutions often brings out social conflict and can result in changes of distribution of income, wealth and power. This has drastic implications that must be considered and addressed in order for members of the public to be in agreeance. Proposing change can be contested by community members but this is where transparency and communication is essential for government officials in order for positive change to occur.

Large populations are complex and cities are messy and disordered places (Johnson, 2008). Due to this complexity, people in cities have had to be creative in developing urban order which is the framework for city life. According to Johnson (2008), urban order is the concept of the operations of cities and can be thought of as an arena in which problems emerge, but is also a place which includes possibilities for their solution. Urban order includes physical infrastructure as well as a moral and social order backed by institutional order comprised of rules and regulations. The institutional order serves as a platform for solving or alleviating the major environmental and social problems that arise from city functions, growth or development (Johnson, 2008). For example, municipal leaders and city planners must work to increase efficiency, while being accountable and transparent in their actions.

In this case, cities act as a driver for innovation because maintenance of an appropriate urban order requires both private and public action and institutional innovation. Innovative private and public 
actors need to take regular and effective steps to solve city problems in the existing urban order. By forming problem-solving environments, cities have been essential vessels for change both city and nation wide. Historically, it can be seen that when a city has experienced critical environmental or health problems, radical innovations in both technology and administration have emerged in cities and contributed to urban growth and further innovation (Johnson, 2008). This perpetuates a cycle of innovation that benefits the city.

Just as cities (and their conflicts) are drivers of innovation, innovation also acts as a driver of cities. Innovation transforms and develops cities and helps them to grow (Johnson, 2008). Some argue that is it important for cities that the growth and development of the creative class workforce should prioritized (Johnson, 2008). The creative class is defined by people whose primary role is to innovate. They identify problems, find solutions, or use existing knowledge in new ways. The creative class brings technical change and economic growth to its cities. In other words, they offer the innovation that cities need to be successful and competitive. Therefore, it is imperative that city planners and stakeholders work to be attractive to this demographic by creating a clean, liveable, diverse, and interesting environment. Having a creative population will inevitably result in a more innovative city.

Innovation in cities can occur in two ways. Firstly, it can increase the understanding of city dynamics. Here innovation is the result of complex city functions that come with problems and need solutions. This is an example of cities as a driver of innovation (Johnson, 2008). Alternatively, it can occur to help promote the development of cities and be attractive to more innovators, thereby fostering a culture of innovation and encouraging further innovation. This is an example of innovation being a driver of cities (Johnson, 2008).

It is suggested that systems of innovation can be a useful tool for understanding how to solve key problems for urban order. Having the ability to solve key problems in crucial in becoming a successful city that is resilient to current and future obstacles. Additionally, a city with a culture of innovation will attract innovative people and form leading edge business and technology which will bring economic growth to the city.

\subsection{Business-friendly}

A business-friendly environment is vital for a city's competitive edge. Without businesses, a city will not generate the wealth that is needed to predicate its life and culture. The implementation of this 
factor requires more than simply having light regulation or low taxes for businesses. It includes promoting a culture of research, innovation an education (Brooke, 2004).

\subsubsection{Business Taxes and Public Services}

While taxes are used to fund public services and infrastructure, they present a significant cost for businesses. Not only do businesses lack direct control of how much tax is levied on them, they also lack direct control of the services and infrastructure that is gained from their tax contributions. This makes it difficult for businesses to consider taxes as a "price" of public services in the same way one would purchase products and services (Monofali, 1993). For this reason, cost of taxes can act as a large deterrent for doing business in a given city and is important for a business to consider when selecting a location. Firms can compare tax costs across cities, provinces or states, and countries. This has increased tax competition among cities to attract businesses. There are multiple factors that can differentiate business taxes among cities.

A firm may examine the tax rate for businesses in a given city and compare rates with other cities. Since business taxes act as a financial burden for businesses, they are likely to be drawn to a city with lower business taxes. Tax deductibility on the other hand is a tool that businesses can use to reduce the significance of tax differentials between cities (Monofali, 1993). For example, if a city has higher tax rates but offers substantial tax deductions for businesses, the tax differential between the two cities is lessened.

Another factor for businesses to consider is the ability to shift higher taxes to another economic agent. This could be through increased prices for their service or product that is paid by customers. For example, if taxes are higher in City A but the firm believes they could charge their customers more for their service in that city compared to City B who has lower taxes, it may be more beneficial to do business in City A. This factor can be researched and estimated by firms, but is generally unknown before moving into that area (Monofali, 1993).

Finally, a factor to consider is whether or not the firms believes the tax rate is matched by public services and infrastructure (Monofali, 1993). Public services offer benefits to their business and employees. Quality and quantity of public infrastructure can increase the efficiency of production and delivery of products and services through better road connections, being well connected through public transit, and other complimentary services in the area. Furthermore, having ample quality public services in the area helps attract qualified talent to the area that are needed to work for the business. Economic 
growth and production are important for a city to be successful. It is important then, for cities to find the balance between fair tax rates, competitive tax deductibles, and quality public services and infrastructure in order to attract new business and stay economically competitive.

Business taxes and infrastructure are important factors for a new business to consider when selecting their location. The level of taxes a business is willing to pay as well as the baseline standard of amenities and infrastructure is unique to each business. There is no perfect formula that can recommend the perfect balance of taxes, tax deductions/ incentives and public services and infrastructure. Cities must find their balance that is competitive against other cities while still maintaining the efficiency of revenue and costs within their jurisdiction. Finding this balance is key to the success of the city.

\subsubsection{Regulatory Policies}

Regulatory policies are important in maintaining control of a city and enforcing certain standards for employers. Sometimes those policies may add undo hardship on existing and new businesses. While regulations such as pollution control and employee safety are essential to providing a sustainable city and happy and healthy workforce, a local economy bombarded with unnecessary regulations stifles growth. These may include high costs and requirement for building permits, licencing and registration of a new business, environmental reviews, and the planning approval process. Streamlining these processes provide for ease for new firms to locate in the city. Providing a simple process for licencing and registration of businesses can sway a new business to locate in one city over another.

\subsubsection{Agglomeration}

Agglomeration economy, as defined by Merriam Webster is "a localized economy in which a large number of companies, services and industries exist in close proximity to one another and benefit from the cost reductions and gains in efficiency that result from this proximity". There is a long history of people and industries concentrating in areas that act as evidence of the existence of agglomeration economies. For instance, why do people and industries crowd into one area rather than spreading out if it is not for the advantages that exist by being in close proximity to one another? People and businesses must be clustering because of inherited advantages that are experienced by clustering (Glaeser, 2010).

There is a debate over whether agglomeration is found due to the natural resources nearby in the area or if it is due to agglomeration economy of other businesses being present. A study by Ellison 
and Glaeser (1999) laid this debate to rest when they found that only about $25 \%$ of industrial concentration can be explained by observable sources of natural advantage. In other words, industries are clustering not because of their proximity to natural resources or location that is beneficial to the industry, for example a logging company being near forests, or shipping companies near ports or other transport. Rather, they are clustering because of the presence of other industry.

It is important to understand what are the mechanisms that make agglomeration beneficial to businesses and how it works to attract new firms. Agglomeration helps to reduce the cost of movement of goods and people. It also is a source of knowledge spillovers which helps cities build a culture of innovation. Agglomeration in a city can act as an attractive feature and contribute to the perception of being business-friendly. The introduction of new firms to a city increases economic production and consequently contributes to the success of a city.

\subsubsection{1 movement of goods and people}

Agglomeration economies can be understood as a result of reduced transportation costs (Glaeser, 2010). There are multiple ways in which agglomeration can help reduce transportation costs. One way focuses on the benefits that comes from reducing the costs of moving goods over space. For example, when a materials supplier locates next to a final goods producer, these firms becomes more productive by saving the costs of shipping. However, the cost of transportation of goods has gotten so inexpensive that this focus is less significant.

A more substantial focus of agglomeration is on the cost of moving people. When people are involved, not only is the monetary costs important to consider, but so is time. Human travel time to and from work, or to and from a supplier of goods is a cost that has great influence on the success of businesses. Value of time is becoming increasingly important for people and even though it is possible to locate goods production anywhere in the world, there is still an advantage from clusters that minimizes the cost of moving people (Glaeser, 2010).

The concept of labour market pooling dates back as far as Alfred Marshall, an American economist in the late 1800's. It is the idea that if there are many employers in an area, then workers can change employers without having to move to different city (Glaeser, 2010). Having flexibility to change jobs is good for workers who do not know where they will be most productive or if productivity of different industries or businesses change over time. Labour market pooling provides resiliency following 
productivity disturbances because workers can leave businesses that have become less productive and move to businesses that are becoming more productive (Glaeser, 2010).

A key to this agglomeration benefit is that industry sectors must be assorted enough so that their industry disturbances are uncorrelated. On the other hand, the industries must be similar enough that workers are qualified to move between them. Labour market pooling has a similar resiliency effect for cities as industry diversification does as discussed earlier in this chapter. Agglomeration of people and businesses reduces the cost of movement but it also increases the resiliency to economic downturns.

\subsubsection{2 knowledge spillovers}

At the core of information-based agglomeration economies lies the idea that knowledge builds on things that are learned through surrounding people (Glaeser, 2010). The interaction of people in urban areas both builds the development of person-specific human capital and increases the rate at which innovation occurs.

Jane Jacobs is a large proponent of knowledge spillovers occurring in dense urban areas. She theorizes that when people in diverse industries interact with one another there is opportunity for idea sharing that would otherwise be lost if those people were not in close proximity (Jacobs, 1969). To quantify this theory, William Kerr conducted a study that found that American patents are increasingly concentrated in specific geographic locations (Kerr, 2008). This suggests that innovators being in proximity to other innovators spawns more innovation. This can be the result of knowledge spillovers or from the competitive nature of innovation and growth.

Businesses want to be in environments where they can continue to grow and innovate. Cities that are experiencing agglomeration become attractive places for new firms which contributors to the overall business-friendliness of that city.

There are many moving pieces that contribute to being regarded as a business-friendly city. There must be a balance of taxes, incentives through tax breaks, and public services and infrastructure. It is also important to consider the ease of starting a business in a city. If the licencing process is too onerous, business may choose to locate in a city where it is easier, faster, and less expensive to get started. Finally, agglomeration provides a large draw to a city for reasons of efficiency, resiliency, and potential for growth and innovation. Each of these factors play a role in the larger factor of success of 
being business friendly. Business friendliness attracts new business to a city which stimulates the economy and leads to economic success of a city.

\subsection{Good Governance}

Good governance is a factor of success according to Brooke (2004). He argues that good governance demands strong civic leaders with visions of the direction they wish for the city to move towards, as well as a strategy to achieve this direction (Brooke, 2004). It is important for all stakeholders to have a voice in the discussion. Stakeholders include government officials, businesses, nongovernmental organizations (NGOs), not-for-profit organizations, and members of the public. Good governance should also include an economic strategy that embraces partnerships with government, local business, and community members. To understand how good governance translates to success for cities, it is imperative to first examine what good governance is.

Governance is not a new concept. It refers to the process of decision-making and the process of implementing those decisions (United Nations, n.d). Since governance is the process of decision-making and implementing decisions, it is also important to examine the actors involved in the processes. Actors in the urban setting include government decision makers, employers, employees, NGOs, trade unions, small scale entrepreneurs, and any other members of the community.

Good governance, as outlined by United Nations (n.d.), has eight major characteristics that include participation, consensus oriented, accountable, transparent, responsive, effective and efficient, equitable and inclusive, and obeys the law. A city's regarded quality of governance is contingent on the level in which a city works to display these characteristics.

\subsubsection{Participation}

Participation by men, women, minorities, and people of all socioeconomic status, culture and ethnicity is a fundamental key of good governance. Participation could be either direct or indirect through legitimate intermediate institutions, stakeholder groups, or representatives (United Nations, n.d). People must be informed on how they can participate and the process should accessible and organized. This allows all members of the community, including the most vulnerable people, to participate in the decision-making process.

A way in which a city can ensure participation is high on the priority list is to create mandatory participatory steps involved in decision processes. In a planning context, cities in Canada and the United States require that community consultation is an integrated part of the planning process. For example, 
in Toronto, community consultation is open to the public and can include a wide variety of subjects such as policy changes, neighbourhood development, or transit expansion. Having mandatory public meetings not only sends the message that participation is valued and important, but it also allows the public to get involved in the decision-making process and have a means of voicing personal concerns.

\subsubsection{Transparency}

Transparent governance means that decisions made and how they will be implemented follows rules and regulations. It also means that information is available and accessible to anybody that may be affected by the decision and its implementation (United Nations, n.d.). The information that is available must also be provided in multiple forms and media to ensure it is accessible to people of all abilities.

\subsubsection{Responsiveness}

In order to achieve good governance decision makers must ensure that institutions and processes aim to address the needs of all stakeholders within a reasonable time (United Nations, n.d.). It is essential that decisions makers put emphasis on addressing all stakeholders and not only those who are the most powerful, influential, or loudest. Decisions makers must acknowledge the needs of disadvantaged people such as minorities or vulnerable populations and respond to their needs equally to be truly responsive.

Ways in which a city can be responsive to their community members is by having an open line of communication where community members can voice their needs This can be through email, PO box, or by holding public meetings. City officials and decision-makers should have access to the emails, letters and comments made by the public so that they are informed of the needs of the community and respond accordingly. While responsiveness is the responsibility of decision-makers, community members are responsible for voicing their needs so that decision makers know what the community needs and wants.

\subsubsection{Consensus Oriented}

With many individual and group needs in a community, there are many view points and opinions about the direction and goals of their city. Good governance requires the ability to mediate different interests within a community to reach broad consensus between groups (United Nations, n.d.). The consensus must be in the best interest of the whole community. Good governance also requires an expansive and long-term perspective on what is needed for sustainable and fair development of the city and how to achieve this development (United Nations, n.d.). A true consensus can only be achieved 
through firm foundation that understands the unique historical, cultural and social contexts of a given city.

In a large city it is difficult for every person to be in agreeance in regard to direction and goals of a city. That is why it is important for citizens to have the opportunity to vote for a representative in their area who best represents their interests. In Toronto council members are voted in that then represent their ward. The goal of this is to try to capture the interests of various groups across the city and achieve a general consensus when city matters are discussed. While the goal of this structure is to simplify and address the needs of the community, some groups may end up not being heard. It is important for cities to continue to listen to the needs of all community members and come as close to a true consensus as possible.

\subsubsection{Follows the Law}

Good governance requires fair legal frameworks that are enforced uniformly. It also encompasses full protection of human rights. Impartial enforcement of laws and human rights requires that enforcement agents are impartial and independent from the decision-making process (United Nations, n.d.).

\subsubsection{Equity and Inclusivity}

A city's well-being depends on ensuring that everyone in the community feels that they have a stake in their society and do not feel excluded from the decision-making process (United Nations, n.d.). This requires that special attention be made that all groups, especially the most vulnerable, have opportunities to improve or maintain their well-being.

\subsubsection{Effectiveness and Efficiency}

The ability for a city to function effectively means that it meets for the needs of the community while making the best use of the resources at its disposal. For a city to operate efficiently, it must balance the cost of providing adequate services and infrastructure with its stream of revenue. The revenue generated by the city should be equal to the cost to provide public services. Efficiency of a city also includes the sustainable use of natural resources and the protection of the environment (United Nations, n.d.).

\subsubsection{Accountability}

Accountability is a large component of good governance. Many stakeholders involved in the decision-making process must be held accountable (United Nations, n.d.). Stakeholders include 
governmental institutions, private sector agents, and civil society organizations. They must be accountable to the public and their own organizations. Generally, an organization or institution should be accountable to those who are affected by the decisions or actions they take (United Nations, n.d.).

With all eight of the factors that inform whether or not a city is achieving good governance it is undeniable that it would be difficult to achieve all eight factors in totality. Furthermore, the subjectivity of the matter makes it difficult to measure and quantify change or progress. However, working towards this ideal with the aim of making it a reality is important for cities to do in order to achieve good governance.

A city that is known for good governance is bound to attract a diverse set of entrepreneurs, businesses, and people. They want to locate in a city that is known to be equitable, transparent, accountable, corruption free and participatory. Good governance is yet another factor involved in attracting people and business that will lead to a city's economic growth and future success. It follows that good governance is a key factor in the success of a city.

\subsection{Distinctive Brand}

For a city to become recognized globally, it must possess a distinctive identity. With the emergence of globalization, cities fall risk to being transformed into what Brookes calls "anywhereville" (Brooke, 2004). Cities must preserve their unique character and development must coordinate with the spirit of the place.

Allowing a city's success to speak for itself is not good enough. With the globalization and ease of movement of capital, goods, and people, cities need to work harder to ensure that capital stays, and new capital enters. In other words, cities need to compete with other cities to attract workers, residents and investors. Creating a distinctive brand requires thoughtful marketing in order to achieve this goal. A brand is a consistent sum of characteristics, images, or emotions consumers experience when they think of a specific symbol, product, service, organization, or location (Oguztimur \& Akturan, 2015). The city in the context of branding can be thought of as a product that has both tangible and intangible attributes. These can include buildings, roads, knowledge, image, culture, and art.

City marketing, also known as destination branding, is defined in Oguztimur and Akturan's work as a "name, symbol, logo, word or graphic that both identifies and differentiates the destination while conveying the promise of a memorable travel experience" (Oguztimur \& Akturan, 2015). Lucarelli and Berg (2011) define it as "the purposeful symbolic embodiment of all information connected to a city in 
order to create associations around it". Hansen (2010) defines it as a policy exercise in economic development by which the municipality promotes its positive attributes in order to convey the message that it is a better place to be than its competitors. While each definition is slightly different, they each demonstrate importance of two factors: to be uniquely attractive, and to bring more economic development, talent, and investment to that city over somewhere else.

City marketing is important in order for people, businesses, and investors to understand the potential of a city and has been taking place for many years. The marketing of urban places has been practiced since the nineteenth century and is derived from the idea of a relationship between image and tourism development (Oguztimur \& Akturan, 2015). City branding can be used to strategically draw sources of economic, political and cultural value (Oguztimur \& Akturan, 2015). It can also be used as a tool to communicate a city's competitive advantage, its quality of life, its history, lifestyle or culture. There is some disconnect however, in the theory of city branding and actual practice.

It is important to also look at city branding through a critical lens. This body of work in this area is fairly new and there has been some lag between research and practice. According to Green et al. (2016), there are three main issues in regards to city branding research.

The first is that city branding and city brand management comes with much uncertainty. It may not even be possible to manage cities as brands. There are many owners, and stakeholders involved in cities. Each member of the public, and each business makes up a portion of the city. There is a high level of complexity involved in trying to control the outward image a city portrays. Every person or business has autonomy to conduct business or act in the way they see fit. A city that tried to influence the behaviour of people is obviously problematic and will not end as a city always predicts.

Secondly, scholars highlight the ethical considerations for city brand management (Green, et al, 2016). For example, selective targeting may encourage partial representation of that city, leaving many people outside of the picture. This is not only an issue in terms of equity, diversity and inclusion of a city, but also has potential to erode a city's natural distinctiveness and diversity that is also important to a city's success.

Finally, city brands are more uncontrollable than a corporate brand. The number of moving parts in a city make branding complex and is difficult to control (Green, et al. 2016). It is important to allow cities to breath and form their uniqueness organically. A distinctive city brand cannot to forced otherwise there is a risk of feeling inauthentic which could be worse than having no brand at all. Despite 
the uncertainty surrounding city branding, cities continue to participate in city branding in an attempt to secure increased economic production, population, and investment.

Whether city branding can actually be controlled or not, many municipalities take part in branding in hopes that it does play a role in attracting residents, business and investors to a city. Although there is not much quantitative literature on the effects of developing a distinctive brand, cities in a highly competitive globalized world need to be proactive in securing economic development, increased population and investment.

Cities, states, provinces, and countries all over the world aim to attract people. In recent years there have been commercials for Montreal, Alberta, California, Newfoundland, and Australia to name a few, each describing their unique sightseeing, lifestyles and live and work opportunities. Waterfront development takes place in Toronto with a slew of rebranding attempts to attract new life to the area.

A study by Cleave and Arku (2015) examined 414 Ontario cities to see how and if they are participating in city branding strategies. They found that $92 \%$ of all communities in Ontario utilized some form of place branding. These results show that cities believe in the power of city branding. Since so many cities around the world are partaking in city branding, it is essential that a city also participate in city branding activities in order to stay competitive. Therefore, creating a distinctive brand is important for the success of a city.

\subsection{Conclusion}

This chapter has explored Brooke's factors of a successful city in detail. It has explained what each factor is and outlined the literature that supports how each factor independently contributes to the success of a city. The findings explored in this chapter have revealed that success can be delivered through a number of different strategies. Sustainable success however, must be built on a wide base with more than one of these key factors present. Just as economic, social and cultural diversity is important for economic growth, diversity in the way in which a city experiences success is important in sustaining that success. Cities must have a combination of success factors in order to maintain growth and prosperity. 


\section{4: Findings and Evaluation of the City of Oshawa}

\subsection{Introduction}

The City of Oshawa has potential to become a successful city as evaluated by Brooke's factors of success. In order to understand how the City of Oshawa can improve and move towards continued success, one must first characterize Oshawa's current position on each factor. This chapter will describe the City of Oshawa's attributes in terms of its diversity, skilled workforce, mobility, quality of life, culture of innovation, business-friendliness, governance, and its branding.

\subsection{Diversity}

\subsubsection{Industrial}

Occupation and industry of the residents of a city can indicate the level of diversity found in the city's economy. Of the City of Oshawa's working population, 9.1\% work in management occupations, $14.9 \%$ work in business, finance, and administration occupations, $5 \%$ work in natural and applied science occupations, $6 \%$ work in healthcare occupations, $10.9 \%$ work in education, law and social, community and government services, $2.4 \%$ work in art, culture, recreation, and sport occupations, $26.9 \%$ work in sales and services occupations, $\mathbf{1 7 . 5 \%}$ work in trades, transport and equipment operators occupations, $1.2 \%$ work in natural resources and agriculture and production related occupations, and the remaining 5.9\% work in manufacturing and utilities occupations (Statistics Canada, 2017).

The City of Oshawa has a wide range of industries in which its residents work. The industry that is most prevalent is the retail trades making up $13 \%$ of the industry in Oshawa, followed by healthcare, construction and manufacturing which make up $11 \%, 8.3 \%$ and $10 \%$ of industry in Oshawa respectively. Other industries present in Oshawa include utilities, whole trade, transportation and warehousing, finance and insurance, administrative, educational services, public administration, accommodation and food services, professional, scientific and technical services, and real estate industries each representing between 3-5\% of the industry in Oshawa (Statistics Canada, 2017)

Ontario's distribution of industry is more spread out than that of Oshawa. The highest percentage of any one industry occupies $11 \%$ of all industry for healthcare and retail and services, followed by $3-8 \%$ for many other industries. Oshawa's industry however, is less evenly spread with a higher percentage of industry being retail and trade (13\%), Healthcare $(11 \%)$ manufacturing (10\%), and Construction (8\%) with many other industries occupying $0.1-6 \%$. This demonstrates that Ontario's 
average industry is more diverse than Oshawa's industry. This can dampen the city's innovation and growth as well as reduce its resiliency to economic downturn as discovered in the literature.

A flaw exists in this method of evaluating Oshawa's industrial diversity. When looking at Ontario averages, it seems as though Ontario is more diverse overall than Oshawa. But Ontario is made up of many cities that may each be contributing a niche industry that is heavily relied upon in one particular city. For example, Sudbury and other Northern Ontario cities rely heavily on mining. But in Ontario, mining makes up only a small percentage of the industry in the province. With this taken into consideration, Oshawa's small differences in the prevalence of certain industries may be remissible.

\subsubsection{Social/Cultural}

Social and cultural diversity is important to the success of a city. To examine the City of Oshawa's social and cultural diversity, 2016 census data was used. Social diversity can be analyzed through the examination of factors in census data such as household income, age of population, living arrangements, and number of children in the household. Cultural indicators include ethnicity and language of the population and immigration.

The City of Oshawa's total population in 2016 was 159,458. The age of the population is relatively evenly spread out over four-year age categories at around 10,000 people in each age range with the exception of people aged 50-54 years of age and 55-59 years of age who represent 13,100 and 12,080 of the population respectively. The only other exception is infants aged 0-4 with a population of 8,777 (Statistics Canada, 2017). This means that the City of Oshawa is relatively older than other cities in Ontario.

The average income of residents of the City of Oshawa is typical for Canada at around $\$ 53,000$ a year according to 2016 census data. The distribution of this income is as follows: People making $\$ 10,000$ or less made up $14.5 \%$ of the population, $\$ 10,000-29,000$ earners made up $31.4 \%, \$ 30,000-49,000$ earners made up 22.5\%, $\$ 50,000-69,000$ earners made up $14.5 \%$, $\$ 70,000-89,000$ earners made up 8.3\%, $\$ 90,000-150,000$ earners made up 7.2\%, and $\$ 150,000+$ made up 1.4\% (Statistics Canada, 2017).

The City of Oshawa is comprised of $82 \%$ non-immigrants, and $18 \%$ immigrants. Each decade, Oshawa welcomed between 3,700 and 5,000 immigrants since the 1980's. Of the total immigrant population, 23\% immigrated from the Americas, mostly from Guyana, Jamaica, Trinidad and Tobago, the United States. 45\% immigrated from countries in Europe such as Italy, Poland, Portugal, United Kingdom, and Germany. A small $4.8 \%$ of the immigration population are from African countries, and $25 \%$ 
are from Asian countries, most heavily from India, Pakistan, Philippines, China, and Sri Lanka (Statistics Canada, 2017).

Language is an important aspect of culture and is therefore a good indicator of culture that can be measured via census data. Mother tongue is the variable that was used for this analysis because it typically represents a significant part of one's personal social and cultural identity. In the City of Oshawa, there are many different mother languages although English and French are the most prevalent in the city. Of the 155,615 responses, 86\% responded "English" and 2\% responded "French". The remaining $11 \%$ of the population identified with having other mother tongues. Among these respondents, less than $1 \%$ spoke Aboriginal languages, 5\% spoke Semitic languages such as Arabic and Maltese, 19\% spoke Slavic languages such as Polish, Ukrainian, and Russian, 8\% spoke Germanic languages such as German and Dutch, $17 \%$ spoke Indo-Iranian languages such as Gujarati, Urdu and Punjabi, 22\% spoke Italic languages such as Italian, Spanish, and Portuguese, 0.2\% spoke Japanese, 0.8\% spoke Korean, and 7.5\% spoke Chinese languages such as Cantonese and Mandarin (Statistics Canada, 2017).

The diversity of ethnic origin of a population of a city can also be a good indicator of social and cultural diversity. A city with a wider range of ethnicities will be more culturally diverse as different ethnic populations have unique cultures. In the City of Oshawa, $71 \%$ of residents are of European origin, 4.6\% are from North American Aboriginal origins, 5\% are from Caribbean origins, $2 \%$ are from Latin, Central and South American origins, 2.2\% are from African origins, and $10 \%$ are from Asian origins (Statistics Canada, 2017).

When examining age and income averages, the population of the City of Oshawa are representative of Ontario's overall averages. The average age in both Oshawa and Ontario as a whole is 41 years old, and the distribution of average income follow the same trends.

Where significant differences lie are within immigration averages, language, and ethnic make-up between Oshawa and Ontario. In Oshawa only $18 \%$ of the population are immigrants, where immigrants as a whole make up 31\% of Ontario's population (Statistics Canada, 2017b). Furthermore, immigrants in Oshawa more often immigrate from the Americas (26\%), Europe (45\%), or Asia (26\%) whereas immigrants in Ontario are largely from Europe (30\%), and Asia (49\%) (Statistics Canada, 2017b).

In regards to mother tongue, $86 \%$ of the Oshawa population speak English where only $67 \%$ of the Ontario population claim English is their mother tongue. The remainder of the population is similar in that there is a large range of mother tongues such as North American Aboriginal languages, Semitic 
languages, Slavic, Germanic, and Indo-Iran languages, Italic languages and Japanese, Korean and Chinese languages. The smaller percentage of English mother tongue found in Ontario's population suggestions a greater cultural diversity than the City of Oshawa.

Finally, ethnic background found in Ontario versus Oshawa's population is a large indicator of social and cultural diversity. A large majority (71\%) of the Oshawa population are of European origin. In Ontario it is still a large majority but less so with $61 \%$ of the population originating from Europe. In Ontario people of Asian ethnicity represented $23 \%$ of the population followed by North American Aboriginal, Caribbean, African and then Latin and Central American representing 4\%, 3\%, 3\%, and 2\% respectively (Statistics Canada, 2017b). Ontario has a more diverse population in regards to ethnicity.

Oshawa's grade: [C] fair. The City of Oshawa is not as diverse as Ontario is as a whole which can present problems for Oshawa such as missed opportunities for gathering unique perspectives that comes with a diverse population and workforce. Lack of diversity in Oshawa also presents a vulnerability to future economic downturn as diversity is a means of ensuring resiliency as determined through study of the literature.

\subsection{Skilled Workforce}

Having access to a skilled workforce is important for the success of a city. One way to a city can measure how skilled their workforce is, is by examining what the highest certificate, diploma, or degree the residents have earned. Another way to measure the opportunity for a skilled workforce in that a city is by examining what kind of educational institutions and training opportunities are available for residents. Important to note however, is that a city that has many higher education institutions, training centres and opportunities does not guarantee that the city's population will be skilled. If a city is not attractive to skilled workers, they may study and train here, then leave to a different city with better work opportunities after graduation. This is why other factors play a role in a cities ability to retain a skilled workforce and be an attractive place to work.

In the City of Oshawa $21.8 \%$ of its residents do not have a high school diploma or equivalency, and $32 \%$ of the population has a high school diploma. $3.4 \%$ of the population have apprenticeship or trades certificates/diplomas and $25 \%$ have a college or CGEP certificate or diploma. $13.5 \%$ of the population has a Bachelors degree or higher and $17 \%$ of the university educated residents have a masters or doctorate degree (Statistics Canada, 2017). Post secondary education field of study range 
from education, humanities, social sciences and business and management, to mathematics, engineering, science, and health.

Another way to indicate the level of skill in a workforce is by examining what kinds of work training programs are available to residents in the city. Training and education institutions present in the city demonstrates that education is a priority. Having higher education institutions in the city provides ease of access to the opportunity to develop skills and knowledge for people living in that city. Not having to travel to attend school makes it possible for residents of that city to pursue higher education.

The City of Oshawa is home to several leading-edge institutions that are contributing to new and innovative research and academic programming. These include Durham College, University of Ontario Institute of Technology (UOIT), Trent University, Lakeridge Health Education and Research Network, Automotive Centre of Excellence (ACE) at UOIT, and Energy Systems and Nuclear Science Research Centre (City of Oshawa, 2019b). Oshawa is also home to the Arch Anthony Meagher training centre that offers adult day credit courses.

The many post-secondary institutions the City of Oshawa has provides a great amount of opportunity for the city to foster a skilled workforce. The City of Oshawa's university and college alone demonstrates a high standard of educational opportunities compared with other cities. Most cities in Ontario are not home to colleges or universities but Oshawa has both. Furthermore, its many leadingedge research facilities allow students to gain a unique and innovative learning experience. However, the education levels of Oshawa residents do not seem to match up with the high amount of educational opportunities available in the City.

When comparing 2016 census data on residents' highest level of education, Oshawa is much less educated than Ontario's average. In Oshawa, $21.8 \%$ of the population do not hold any type of diploma whereas only $17 \%$ of Ontario's population as a whole does not hold a diploma. In Ontario, $26 \%$ of the population hold a Bachelor's degree or higher, while only $13.5 \%$ of Oshawa's population have a university degree. The highest education level of most Oshawa residents is either a high school or college diploma with $32 \%$ and $25 \%$ respectively.

Low education levels in Oshawa are not a result of a lack of educational institutions in the City. Thousands of students graduate from the many programs offered at UOIT, Trent, and Durham College each year. The problem here can be attributed to Oshawa's ability to retain these graduates in the City in which they were trained, and attract educated newcomers. Only if a city is attractive for skilled 
workers will these individuals stay. This is key in attracting new businesses who wish to employ skilled workers and in growing the city's economy and population.

Oshawa's grade: [B] good. Oshawa provides excellent opportunities for its residents to obtain high education and skill. However, the reliance on industrial jobs such as those on the GM production lines may be preventing Oshawa residents from seeking higher education. Additionally, other factors such as quality of life, diversity and mobility in the City may play a role in Oshawa's inability to retain their graduates leading to a workforce that is less skilled than Ontario averages.

\subsection{Mobility}

\subsubsection{Local}

The City of Oshawa is serviced by many surface level bus routes which are operated by Durham Region Transit (DRT). Buses run frequently on main roads such Simcoe St, Taunton Rd, and King St. Stevenson Rd, Centre St, Harmony Rd, Bond St, Rossland Rd, and on less busy roads. It is possible to travel anywhere around Oshawa using DRT alone.

The Durham Region Transit buses run as early as 5:30 AM, to as late as 1:15 AM on busy routes such as Simcoe St. or King St. Less busy bus routes start service later in the morning and end earlier in the evening but are generally available during daytime and evening hours. Most routes run from 6 AM to 11 PM making transit a good option for people who do not own cars, cannot drive, or choose to use transit (Durham Region Transit, 2019).

The fare to use DRT depends on the mode of payment and age of rider. Adults who pay cash are charged $\$ 3.75$. A package of a ten-trip pass costs $\$ 31.50$ which equals $\$ 3.15$ per trip. PRESTO users pay $\$ 3.15$, and a monthly PRESTO pass costs \$117.00. Youth aged 12 and under and seniors aged 65 and older pay $\$ 2.50$ cash, $\$ 21.00$ for a ten-pass, and $\$ 2.10$ for PRESTO or $\$ 65$ for a monthly PRESTO pass. Youth aged 13-19 pay $\$ 3.75$ cash, $\$ 28.00$ for a ten-pass, $\$ 2.80$ if using PRESTO, or $\$ 93.50$ for a monthly PRESTO bus pass. People who are eligible for the Ontario Disability Support Program (ODSP) can acquire a monthly paper pass for $\$ 46.00$ (Durham Region Transit, 2019). There is also fare integration for passengers who transfer from DRT to the GO stations. Passengers who connect to the GO transit will only pay $\$ 0.80$ for their DRT trip.

In the City of Oshawa, trips made by transit represented $5 \%$ of all trips compared to $3 \%$ of trips in Durham Region as a whole (Transportation Tomorrow Survey, 2018). This means that people in 
Oshawa use transit more often than the average in Durham Region. Durham Regional Transit is a functional transit system that provides mobility to the people in Oshawa and surrounding municipalities in Durham. Transit in Durham will continue to grow its service as ridership increases.

The City of Oshawa's bus system is one that runs frequently, and is reliable. Expanding to a higher-order transit system would cause undue pressure on Oshawa's growth. The Growth Plan for the Greater Golder Horseshoe requires that areas that are served with bus rapid transit (BRT) or light rail transit (LRT) have 160 residents and jobs combined to meet the major transit station area standards (Places to Grow Act, 2017). This density would be difficult for Oshawa to achieve at this time and could result in a system where operating costs exceed revenue.

Additionally, Oshawa's population is not nearly as large as populations in other cities when they decided to invest in LRT. For example, both Calgary and Edmonton had populations of around 500,000 when they built their LRT systems. Oshawa still has a large amount of growth to do before BRT or LRT is appropriate for the city. Until then, the bus system does an adequate job of providing mobility to the Oshawa population (Hamilton Rail Initiative, 2011).

What the City of Oshawa should work to improve however, is ridership. Transit ridership in Oshawa is low and the transit system and residents would benefit from an increased ridership because it would result in an increased need for transit, more revenue and therefore more investment in the quality of service provided. Oshawa should aim to make transit more attractive to selective users to increase ridership numbers. Increased transit-oriented development and user charges associated with driving and parking could act as starting points for improvement in this realm.

\subsubsection{Global}

While the City of Oshawa does not have direct access to the rest of the world via air travel, it does have indirect access. The City of Oshawa has a GO train station that can take passengers to Union station in Toronto where they can connect to the UP express that travels to Pearson Airport. The trip from Oshawa to Toronto's Union station takes one hour. Followed by the UP express which takes about 25 minutes. In total, a trip from Oshawa to Pearson International Airport is approximately 1 hour and 45 minutes including transfer time, by public transit. The price to take the $\mathrm{GO}$ train from Oshawa station to Union station is $\$ 11.20$ and the price for the UP express to Pearson is $\$ 12.35$ for an adult, totalling $\$ 23.55$ one-way. Some discounts are available for children, students, and seniors, and people using PRESTO cards rather than cash. 
While Oshawa does not have access to the rest of the world via an international airport of their own, Oshawa's proximity to Toronto allows residents to take advantage of the global access that Toronto has. Other cities in Ontario are not in such favourable locations and may even have to fly to Toronto from remote airports in order to access the rest of the world. Location in relation to Toronto Pearson Airport is a strength for the City of Oshawa's access to global mobility.

Oshawa's grade: [B] good. Oshawa has a reliable transit system that works to make the City accessible for all residents. The bus system is appropriate for Oshawa's population size. Oshawa's proximity to Toronto's Pearson International Airport allows for global access in less than 2 hours. The City of Oshawa meets all expectation for basic mobility in a city but could offer more to achieve excellence.

\subsection{Quality of Life}

\subsubsection{Physical Environment}

The City of Oshawa features attractive physical environment features that add to a person's quality of life. It is located on Lake Ontario and has a long waterfront trail from the pier on the east end of Oshawa connecting through to the wider Lake Ontario Trail. There are several natural areas in Oshawa including Oshawa Valleylands Conservation Area, The Oshawa Valley Botanical Gardens, Cedar Valley Conservation Area, Harmony Valley Conservation area, and many parks and greenspaces and small ravines. In the City of Oshawa, one is never far from greenspace which contributes to a higher quality of life. However, the lakefront of the City of Oshawa could use improvements in order to fully take advantage of the asset.

Many cities in Ontario are located on Lake Ontario and have significant natural areas that contribute to making them desirable places to live. Toronto, Oakville and Hamilton are all directly on the lake and many cities that are not directly on the lake have substantial natural areas.

\subsubsection{Climate}

The City of Oshawa is located in Southern Ontario. Southern Ontario has a humid continental climate with four distinct seasons. The average high in July, or peak summer season is between 25 Celsius to 28 Celsius. The average high for January, or peak winter season ranges from -6 Celsius to 0 Celsius. The record high temperature in Southern Ontario is 45 Celsius and the record low is -30 Celsius. Needless to say, the City of Oshawa can reach extreme hot and cold temperatures. However, most of the year tends to be quite mild and comfortable. 


\subsubsection{Crime}

Crime is an important factor in one's quality of life. People want to live in cities that are safe so that they feel comfortable walking their neighbourhood, and feel secure in their home. A feeling of safety and security adds to a person's quality of life so cities with lower crime rates corelate with having a higher quality of life. A crime rate is the number of criminal incidents reported to, and substantiated by police services per 100,000 population. Durham Region, in which Oshawa is situated, received the fourth lowest overall crime rate amongst comparator cities in 2017. Durham Region had a crime rate of 2949 per 100,000 population in 2017. To compare, Toronto police services had a rate of 3863 per 100,000 population, and Waterloo had a rate of 5189 per 100,000 population (Mitchell, 2018).

\subsubsection{Social Services}

Durham Region has a wide variety of social services that are available to all residents in Durham including the City of Oshawa. They offer services on business affairs and financial management, children's services, family services, housing services, income and employment support services, and long-tern care and services for seniors (Durham Region, 2019). Durham Region aims to reach the highest of standards for its residents. In 2015 they received the Order of Excellence through the Canada Awards for Excellence (CAE). This award goes to organizations that work to significantly improve the quality of life of Canadians. In recent years, Durham Region has been granted Gold certification in the Excellence, Innovation and Wellness standard which demonstrates the Region's commitment to long-standing excellence.

\subsubsection{Arts and Culture}

The City of Oshawa has many opportunities to share and experience arts and culture in the city. A cultural map found on the City's website shows more than 200 community cultural groups, cultural businesses, cultural facilities and venues, festivals and events, heritage sites and properties, and public art. Some of these features include the Robert McLaughlin Art Gallery, Oshawa-Whitby Kiwanis Music Festival, Canadian Conservatory of Music, photography, art, and design classes, cultural recreation clubs, and various community centres among many others (City of Oshawa 2019a).

\subsubsection{Income and Employment}

In 2018 , Oshawa had an employment rate of $65.1 \%$. This means that $65.1 \%$ of the total population 15 years or older held employment. Alternatively, the unemployment rate is $5.1 \%$. This is below Ontario's unemployment rate of $6.0 \%$ and the GTA's unemployment rate of $6.6 \%$. According to 
2016 census data, the median total income for residents in the City of Oshawa is $\$ 33,493$ which is lower than Ontario's median income (Statistics Canada, 2017). So, while less Oshawa residents are unemployed than those in other Ontario cities, they are earning less than average wages in comparison.

\subsubsection{Cost of Living}

The cost of living in the City of Oshawa is less than it is in the city of Toronto but is about equal to the cost of living in other municipalities in the Greater Toronto Area (GTA). According to Luyt et al. (2017), The cost of food for a family of four living in the City of Oshawa is $\$ 8,105.60$. The average cost to buy a home in Oshawa in 2017 is $\$ 615,064.00$ but this price varies depending on location, age of the home, condition of the home, and additional features that come with the home. Average rent in Oshawa for a 1-bedroom apartment is $\$ 717.00$ per month, a 2-bedroom is $\$ 865.00$ per month, and a 3bedroom is $\$ 1,375.00$ per month (Luyt et al., 2017).

In the City of Oshawa, a living wage is approximately $\$ 17.00$ per hour. This number reflects what a worker would need in order to have a decent quality of life that includes food, clothing, shelter, recreation, and one modest vacation per year. The median income in the City of Oshawa is $\$ 33,493$ which breaks down to $\$ 17.18$ per hour. This means that half of working Oshawa residents are earning enough money at work to sustain a decent quality of life, and half are not.

Oshawa's living wage is on the high end compared to other regions in Ontario. The average living wage in Ontario is $\$ 16.50$. Ontario's median income for individuals is $\$ 33,530$ which can be broken down to $\$ 17.20$ per hour. It can be concluded that it costs more than average to live in Oshawa, while Oshawa residents earn slightly less.

Oshawa's grade: [B] good. The City of Oshawa has a low crime rate making residents feel safe. It also boasts lower-than-average unemployment rates compared to Ontario's average. However, the cost of living in Oshawa is slightly higher than Ontario's average for a city while earning lower wages than Ontario's average.

\subsection{Culture of Innovation}

The City of Oshawa recognizes the importance of having a culture of innovation instilled in the city. They have made efforts to incubate opportunities for innovation in education, and professional realms. 
There are several leading-edge institutions in the City of Oshawa that are driving original research and academic programming. Post-secondary institutions in Oshawa have unique mandates to collaborate with private sector industry partners to develop innovative business solutions (City of Oshawa, 2019b). Partnerships between academics and industry enables local companies to access new and competitive solutions. Opportunities for innovation include capstone projects, internships, competitions, and state-of-the-art research facilities that positively impact the marketplace and foster a culture of innovation.

Durham College Office of Research Services, Innovation, and Entrepreneurship (ORSIE) has a direct impact on the economic advancement and sustainability of the region by working with small and medium-sized businesses to help them innovate, commercialize, and develop their ideas so they can grow in the marketplace (City of Oshawa, 2019b).

The University of Ontario Institute of Technology (UOIT) contributes to the acceleration of economic growth and social innovation through relevant collaborative research with industry and community partners. The university prides itself on its strategic research focused on advanced manufacturing, sustainable energy and the building of smart communities. Trent University also contributes heavily to the innovative and ground-breaking research that in conducted in Oshawa (City of Oshawa, 2019b).

Leading edge facilities in Oshawa allow for experimentation and innovation in industry. Lakeridge Heath Education and Research Network (LHEARN) trains 1,600 students annually in healthcare and many research studies and clinical trials have taken place there. UOIT's Automotive Centre of Excellence (ACE) is a $\$ 100$ million multi-purpose testing product that can create extreme weather conditions such as wind tunnels, earthquakes, extreme heat and humidity, and arctic blizzards used to test a variety of products. Finally, UOIT's Energy Systems and Nuclear Science Research Centre is a facility that facilitates research in geothermal, hydraulic, hydrogen, natural gas, nuclear, solar and wind energy technologies (City of Oshawa, 2019b). Each of these centres facilitate innovation in the field of healthcare, production, and energy sectors.

UOIT, Durham College, Fleming College, and Trent University have worked together with Spark Centre and the Greater Peterborough Innovation Centre (GPIC) to create the FastStart program in the City of Oshawa. FastStart is a new resource designed to help university and college students develop entrepreneurial skills and convert innovative business ideas into successful companies. Additionally, 
THRIVE is a start-up incubator program located in Downtown Oshawa that offers services for entrepreneurs to help them accelerate their success in the technology sector (City of Oshawa, 2019b).

Oshawa's grade: [A] excellent. Based on Oshawa's programs alone, innovation is proven to be a priority for the City of Oshawa. The City makes great effort to nurture its culture of innovation through various post-secondary education options, partnerships with industry, and innovation programs.

\subsection{Business-friendly}

\subsubsection{Business taxes}

Businesses must pay taxes to the city, province, or country in which they are located. The cost of these taxes contributes to the cost to run a business. Business taxes are different across cities and can be a reason that a business chooses to locate in one city over another. Taxes that businesses consider are Corporate Taxes, Income Taxes, and Employee Benefit Costs. Businesses will choose a city that has a favourable balance between tax costs and public services that works best for them.

In the City of Oshawa, the combined provincial and federal corporate taxes as of July 2018 differ depending on the type of business. General Manufacturing and Processing Corporate businesses pay 25\%, General; Active Corporate Business Income pays 26.5\%, Small Private Businesses with an Income of up to $\$ 500,000$ pay $13.5 \%$, and General Active Private Business Income pay $26.5 \%$ (City of Oshawa, 2018).

Personal income taxes in Oshawa are also directed by the provincial and federal government. Taxes range from $20-53 \%$ depending on income. People who make $\$ 42,960$ or less pay $20.05 \%$, where people who make $\$ 200,000$ or more pay $53.53 \%$ (City of Oshawa, 2018)

Employee benefits costs make up a large portion of a business costs. There are certain costs that are mandatory for businesses to pay the common practice for employers in the city may be different. In the City of Oshawa, employers must contribute to the Canada Pension Plan (CPP) $4.95 \%$ to a maximum of $\$ 2,593.80 /$ year. Employers must also pay $1.66 \%$ to the Employment Insurance Commission. Employers are required to pay $4 \%$ for vacation yearly, although $6 \%$ is common practice. It is also mandatory to allow 9 days or 3.6\% paid public holidays yearly, although 11 days (4.4\%) is common practice (City of Oshawa, 2018). In all, the mandatory total for employee benefits costs is $22.53 \%$ but common practice brings this total to $31.6-35.6 \%$. 
On average in Ontario, employee benefits will typically be about $15 \%$ of payroll for a small company and about 30\% for a large company (TechEdge, 2013). This puts Oshawa averages on the higher end of business costs. While this might be attractive for workers, it may act as a deterrent for businesses to locate in Oshawa.

\subsubsection{Regulatory Policies}

Firms looking to start a business in the City of Oshawa must first obtain a business licence. No trade can be conducted whether it is for profit or not for profit without a business licence (City of Oshawa, 2016). To obtain a business licence, one must submit an application with the City of Oshawa office of the Director. A licence fee is also charged and is set out by the City's General Fees and Charges By-law and depends on business type. All of the important information to obtain a licence and start business in the City of Oshawa is available online, or at the City's city hall.

While fees vary from city to city, the licencing process and fee is standard practice in any city in Ontario. The City of Oshawa does not add any extenuating processes to starting a business therefore in regards to regulatory processes, it is as business-friendly as many other cities.

\subsubsection{Agglomeration}

In the City of Oshawa, many businesses cluster downtown around King St and Bond St, and Simcoe St. There may be some opportunity for an agglomeration economy but businesses may choose to locate in Toronto for more established agglomeration economies unless they are seeking a niche market in Oshawa.

Oshawa's grade: [C] fair. While the City of Oshawa does not place excessive burden on businesses wishing to locate there, it is on the high end of employee costs. Furthermore, the City of Oshawa may not be able to offer such a robust agglomeration economy as one that would be experienced in Toronto.

\subsection{Good Governance}

Good governance is a difficult factor to quantify. It requires that a government encourage participation, transparency in their processes, responsiveness to their citizens' needs, is consensus oriented, follows the law, strives for inclusivity, equitability, effectiveness, efficiency, and accountability.

Municipalities in Ontario such as the City of Oshawa are governed under the Ontario Planning Act (1990). Under this Act, it states that information and materials shall be made available to the public (s.1.0.1). The purpose of the Act is to ensure that planning processes are fair and equitable by making 
them open, accessible, timely, and efficient, to encourage co-operation and co-ordination among various interest groups, and to recognize the decision-making authority at large, and ensure accountability of municipal council in planning (s.1.1). The City of Oshawa must follow the policy regulations outlined by the Planning Act (1990) which ensures a level of good governance experienced across all cities in Ontario.

Oshawa's grade: [B] good. The City of Oshawa meets the legislated requirement for a planning process that ensures good governance across all municipalities in Ontario. Oshawa should continue to keep their process transparent, participatory, responsive, equitable, effective, efficient, inclusive, and accountable.

\subsection{Distinctive Brand}

Distinctive branding can be a useful tool for attracting visitors, new residents, and businesses to a city. The city branding efforts that the City of Oshawa has engaged in are as follows.

Since Oshawa officially became a "city" in 1924, it has heavily relied on the auto industry as its main economic driver. In the late 1800's it was home to the McLaughlin Carriage Company which would eventually become General Motors Canada Limited. By 1920 GM Canada employed over 3,000 people and Oshawa was nicknamed "Canada's Motor City". In recent decades however, the decline (and soon to be termination) of GMs production in Oshawa has left Oshawa with a lack of identity or brand.

As a response, in 2003 the City of Oshawa's economic development department established a media relations group to improve communications and ensure a positive image is displayed for Oshawa. The group that was created was called Corporate Communications and Marketing. The new group's responsibilities include creating the City of Oshawa Visual Identity Manual, corporate advertising for Oshawa, social media, news archives, "Our Oshawa" annual highlights publication, "Inside Oshawa" enewsletter, and online communications strategy and policy (Robinson, 2018).

In 2015, the Corporate Communications and Marketing group published the City of Oshawa Corporate Visual Identity Manual. The purpose of this manual is to express Oshawa's corporate identity through the City crest/coat of arms, a city logo, and fire and police services badges. The City's use of the crest/coat of arms, logo, and badges are meant to distinguish the City of Oshawa from other municipalities.

Despite Oshawa's close proximity to Toronto, it is often overlooked as a potential place of population or economic growth. This may be partially attributed to its lack of a distinctive brand other 
than being seen as a largely suburban area. Other mid-sized cities in Ontario made good use of the significant industry in the area to create an identity or brand. For example, Sudbury's nickel mines and "the big nickel" make it more than simply a mining town and has transformed its image into an interesting place to visit, work, or live. On a larger scale, Toronto is recognized globally by its CN tower, and its impressive musical and visual arts as well as its multiculturalism. The City of Oshawa needs to stand out from the rest of the Ontario cities if its wants to be recognized and attractive to visitors and future residents.

Oshawa's grade: [D] poor. Beyond logos, crests and badges, the City of Oshawa does not make an extensive effort to establish a distinctive brand. Features such as attractions, large-scale public art and other distinctive features that draw people to a city are lacking in Oshawa. Because of this, Oshawa is not thought of as a fascinating place to live, work, or tour. This ultimately hurts Oshawa's growth potential and could be working against Oshawa's ability to becoming a well-rounded successful city.

\subsection{Conclusion}

This chapter has described the City of Oshawa in terms of diversity, skilled workforce, mobility, quality of life, culture of innovation, business-friendliness, governance, and city brand. Now that an understanding of Oshawa's characteristics has been described, it is possible to evaluate where Oshawa stands in terms of success under the umbrella of each factor. The facts found in this chapter will inform ideas of how the City of Oshawa can improve and continue down a path of attainable and sustainable success.

\begin{tabular}{|l|c|}
\hline \multicolumn{1}{|c|}{ City of Oshawa Report Card } & \\
\hline Diversity & C \\
\hline Skilled Workforce & B \\
\hline Mobility & B \\
\hline Quality of Life & B \\
\hline Culture of Innovation & A \\
\hline Business-friendly & C \\
\hline Good Governance & B \\
\hline Distinctive Brand & D \\
\hline Average grade: & C+ \\
\hline
\end{tabular}




\section{5: Discussion}

\subsection{Summary of Findings}

This research first evaluated Brooke's key factors of success. These included industrial, cultural and social diversity, skilled workforce, mobility, quality of life, culture of innovation, businessfriendliness, good governance, distinctive brand, and urban renewal. Brooke stated that there are nine factors to the success of a city but did not offer any evidence or research as to why these factors are included in his model. Before this model could be applied to any cities as an evaluation tool, each factor had to be examined individually to establish if and how it directly contributes to the success of a city.

A literature review of each factor revealed that eight of Brooke's nine factors of success had substantial evidence to suggest that they uniquely contributed to the success of a city. These factors included diversity, skilled workforce, mobility, quality of life, culture of innovation, business-friendliness, good governance and distinctive brand. The success that each factor contributed to was expressed through increased economic activity or growth, population growth, or general population satisfaction or happiness.

Only one of Brooke's factors (urban renewal) did not have conclusive research on how it contributes to the success of cities. Urban renewal has shown success in some cities but has been destructive in others. For that reason, it was determined that it is not an independent factor of success in a city and should not be included as a measure of success.

Once success factors were established and justified through an extensive review of the literature, it could then be applied to the City of Oshawa. The City of Oshawa was evaluated based on census data where possible, as well as by attempting to quantify Oshawa efforts by means of programs, processes, and standards. These were then compared to Ontario's average to gain an understanding of whether Oshawa was exceeding Ontario averages, meeting them, or lagging for each factor.

What the evaluation revealed is that the City of Oshawa places great importance on fostering a culture of innovation. Most of the factors in Oshawa are meeting Ontario averages but are not exceeding them such as Oshawa's skilled workforce, mobility, quality of life, and governance. In some areas Oshawa is lagging behind such as in its business-friendliness or distinctive branding. What this evaluation has discovered is that the City of Oshawa is a work-in-progress with potential for improvement in several factors of success. 
There is work to be done for Oshawa to become the successful city it has the potential to be in relation to the factors of success explored in this research paper. The findings of this research will allow planners and city staff to focus on the key areas of improvement. Targeted improvement in a few struggling factors will result in the most positive change for Oshawa and can set the stage for more positive change in the future.

A gap in the evaluation of Oshawa is not considering the age of the city. The City of Oshawa is a new city, only gaining a city status in 1924. Things take time to grow and develop and reach their full potential and cities are no exception. During the City of Oshawa's short 95 years as a city, it has developed a downtown, a commercial hub, a college, a university, and many more positive attributes.

Each of these accomplishments were not achieved immediately. University of Ontario Institute of Technology is less than 15 years old but today it contributes to Oshawa's growth of a skilled workforce, culture of innovation, and business-friendliness. As the City of Oshawa continues to grow, more businesses will be attracted to the city, the population may grow large enough to support additional transit, and the city can continue to grow its brand.

Other cities in Ontario that are comparable to the City of Oshawa such as Oakville and Hamilton are older and more mature than Oshawa. These cities have had more time to develop, grow and learn. The City of Oshawa has many improvements to make in order to fulfill its potential but this will take many years.

\subsection{Relevance to Planning}

This research has added to the literature of understanding the many components that are involved in creating a successful, thriving city. Understanding what makes a city successful will allow city planners to be intentional with their policy making, development, and overall goals. They can also be mindful of how each factor discussed in this research paper will affect the city in a positive way.

If cities are not evaluated, it is impossible to know what can be improved upon. Evaluation is an important part of learning, growth, and future success. This paper has evaluated the City of Oshawa which allows city staff to recognize Oshawa's strengths and weaknesses and strive to improve the areas that need improvement. This paper has discovered that the City of Oshawa has a weakness in its distinctive branding, business-friendliness, and diversity. It is doing well in terms of having a skilled workforce, mobility, quality of life, and governance. It is excelling in its culture of innovation. Knowing these strengths and weaknesses gives planners and city staff the opportunity to work towards 
improvement of the factors needing improvement. The City of Oshawa can leverage their strengths in order to improve other factors.

\subsection{Limitations to Application}

Planning can be a tool to achieve success through the use of the factors discussed in this paper. However, there will always be outside factors that cannot be planned for. The City of Oshawa's early growth can be attributed to GM production in the city. It was a provider of thousands of jobs that paid well and offered excellent benefits to industry workers as well as the growth of Oshawa's economy and population. Many residents in Oshawa depended on GM production for their livelihoods. When GM announced that the production in Oshawa would be coming to an end, many Oshawa residents are faced with unemployment without having any other industry to turn to in Oshawa. Many of these residents also lack the necessary skills required to transition easily into a different high-paying job.

There is little the City of Oshawa can do to mitigate the hardship many Oshawa residents will experience due to the GM closure. What Oshawa can do is plan for resiliency during these times by increasing industrial diversity, skilled workforce, and business friendliness among other related factors. Each factor has shown to contribute to success in a unique way. Having strong foundations in each factor will allow a city and its residents more opportunity to share success despite outside forces that bring unanticipated consequences.

More research should be done to examine how cities can be more resilient to economic downturn or disruption like what Oshawa is currently experiencing. Researchers should ask what tools cities can use in order to protect themselves from unanticipated happenings. Despite achieving a high standard of the success measures discussed in this paper why might cities still face negative consequences to uncontrollable circumstances?

\subsection{Conclusions}

Planning plays a large role in ensuring the success of a city. Cities can work to build industrial, social, and cultural diversity, have a skilled workforce, ensure sufficient mobility within the city, provide a high quality of life and foster a culture of innovation. Cities can seek to become more businessfriendly, govern their cities well, and build a distinctive brand.

While planning allows the city to set standards that act as a framework to ensuring success, things may happen that are outside of the control of the city and its planners. The City of Oshawa is a city in progress making strides to meet its growth potential. While the closure of GM's auto production 
has caused some instability for the City of Oshawa and its residents, work towards achieving high standards in each factor will ultimately help guide Oshawa towards success. 


\section{References}

APTA (2003), Public Transportation National Summaries and Trends Statistics, American Public Transit Association (www.apta.com/research/stats).

APTA. (2018). 2017 Public Transportation Fact Book (68th ed.). Washington, DC: American Public Transportation Association.

APTA. (2018). Public Transportation Benefits. American Public Transportation Association. Washington, DC. Retrieved from https://www.apta.com/mediacenter/ptbenefits/Pages/default.aspx.

Aschauer, D. A., and Campbell, E. J., (1991), Transport Spending and Economic Growth, Earthward: The Journal of Environmental and Social Responsibility, vol. 4, No. 38, Sept., 1991.

Besser, L. M., and Dannenberg, A. L., (2005), "Walking to Public Transit: Steps to Help Meet Physical Activity Recommendations," American Journal of Preventive Medicine, Vo. 29, No. 4 (www.acpm.org); at www.cdc.gov/healthyplaces/articles/besser_dannenberg.pdf.

Brooke, N. (2004). FOCUS ON GLOBAL ISSUES: WHAT MAKES FOR A SUCCESSFUL CITY. Real Estate Issues, 28(4), 28-29. Retrieved from http://ezproxy.lib.ryerson.ca/login?url=https://searchproquest-com.ezproxy.lib.ryerson.ca/docview/213999891?accountid=13631

Castelazo, M. D., and Garrett, T. A., (2004), "Light Rail: Boon or Boondoggle," The Regional Economist. Retrieved from www.stlouisfed.org/publications/re/2004/c/pages/light_rail.html

City of Oshawa. (2016). Business Licensing By-law 120-2005. City of Oshawa Retrieved from https://www.oshawa.ca/uploads/16/LicensingBy-law120-2005.pdf?ts=635738520555490657.

City of Oshawa. (2018). Oshawa Taxes. City of Oshawa Retrieved from https://www.oshawa.ca/business-and-investment/taxes.asp

City of Oshawa. (2019a). Arts and Culture. City of Oshawa Retrieved from https://www.oshawa.ca/things-to-do/arts-and-culture.asp

City of Oshawa. (2019b). Innovation. City of Oshawa Retrieved from https://www.oshawa.ca/businessand-investment/innovation.asp

Clarke, J., \& Wise, N. (2018). Urban Renewal, Community and Participation, Springer, Retrieved from https://ebookcentral-proquest com.ezproxy.lib.ryerson.ca/lib/ryerson/reader.action?doclD=5379753

Cleave, E., \& Arku, G. (2015). Place Branding and Economic Development at the local level in Ontario, Canada. GeoJournal, 80, 323-338. doi:10.1007/s10708-014-9555-9

Crain \& Associates (1999), Using Public Transportation to Reduce the Economic, Social, and Human Costs of Personal Immobility, Report 49 TCRP, TRB (www.trb.org).

Desfor, G., Keil, R., Kipfer, S. \& Wekerle, G., (2006). From Surf to Turf: no Limits to Growth in Toronto?, Studies in Political Economy, 77:1, 131-155, DOI: 10.1080/19187033.2006.11675115 
Durham Region. (2019). Social Services. City of Oshawa Retrieved from https://www.durham.ca/en/regional-government/social-services.aspx.

Durham Region Transit. (2019). Durham Region. Retrieved from https://www.durhamregiontransit.com/en/index.aspx

Ellison, G., and Glaeser, E. (1999). The geographic concentration of industry: Does natural advantage explain agglomeration? American Economic Review 89 (2): 311- 16.

Findlay, A. and Rogerson, R. (1993) Migration, places and quality of life: voting with their feet, in: A. CHAMPION (Ed.) Population Matters, pp. 33-49. London: Paul Chapman.

Florida, R. (2018, April 20). How airports drive economic growth. Toronto Star. Retrieved from: https://www.thestar.com/opinion/contributors/2018/04/20/how-airports-drive-economicgrowth.html

Glaeser, E. L. (2010). Agglomeration Economics. The University of Chicago Press, 1-15. Retrieved from http://www.nber.org/chapters/c7977

Glaeser, E. L. (2005). Smart Growth: Education, Skilled Workers, \& the Future of Cold-Weather Cities. Harvard University. Retrieved from https://www.hks.harvard.edu/sites/default/files/centers/taubman/files/skilledcities.pdf.

Glaeser, E. L., Kallal, H. D., Scheinkman, J. A., \& Shleifer, A. (1992). Growth in Cities. Journal of Political Economy, 100(6), 1126-1152. Retrieved from https://www-jstororg.ezproxy.lib.ryerson.ca/stable/2138829?pqorigsite=summon\&seq=1\#metadata_info_tab_contents.

Green, A., Grace, D., \& Perkins, H. (2016). City Branding Research and Practice: An integrative review. Journal of Brand Management, 23, 252-272. doi:10.1057/bm.2016.8

Hamilton Light Rail Initiative. (2011). The facts. Retrieved from http://hamiltonlightrail.ca/the-facts

Hart, S., Denison, D. \& Henderson, D. A. (1988) A contingency approach to firm location: the influence of industrial sector and level of technology, Policy Studies Journal, 17, pp. 599-629.

Haughwout, A. F., (2000), The Paradox of Infrastructure Investment, Brookings Review (www.brookings.edu), pp. 40-43.

ICF (2008), The Broader Connection between Public Transportation, Energy Conservation and Greenhouse Gas Reduction, American Public Transportation Association (www.apta.com); at www.apta.com/research/info/online/documents/land_use.pdf.

Jacobs, J. (1969) The Economy of Cities. New York: Vintage, 1969. Cities and the Wealth of Nations: Principles of Economic Life. New York: Vintage, 1984.

Johnson, B. (2008). Cities, systems of innovation and economic development. Innovation: Management, Policy \& Practice, 10(2), 146-155. Retrieved from http://ezproxy.lib.ryerson.ca/login?url=https://search-proquestcom.ezproxy.lib.ryerson.ca/docview/203606816?accountid=13631 
Kerr, W. R. (2008). The Agglomeration of US Ethnic Inventors. Harvard Business School. Retrieved from https://www.hbs.edu/faculty/Publication Files/09-003_16344029-8293-41d8-94d516427eb72f1e.pdf.

Liebregts, J. (2014, November 10). Life after the decline of the auto industry in Durham Region. DurhamRegion.com. Retrieved from https://www.durhamregion.com/newsstory/4977125-life-after-the-decline-of-the-auto-industry-in-durham-region/

Litman, T. (2011). Calculating Public Transit Benefits and Costs: Best Practices Guidebook. Victoria Transport Policy Institute. Retrieved from https://books-scholarsportalinfo.ezproxy.lib.ryerson.ca/en/read?id=/ebooks/ebooks0/gibson_cppc/2012-0514/1/10534499.

Liu, C., (2005), Orange Line Eases A.M. Rush on 101 Freeway: Study Finds A Slight Improvement Traffic Flow Since The Opening Of The Valley Busway - Although Most Motorists May Not Feel The Change, Los Angeles Times (www.latimes.com), 30 Dec. 2005.

Lucarelli A., Berg P.O. (2011). City Branding: A State-of-the-art Review of the Research Domain. Journal of Place Management and Development 4(1): 9-27.

Luyt, G., Mifsud, A., Aquanno, S., \& Bryant, T. (2017). Living Wage in Durham Region. Community Development Council Durham. Retrieved from http://www.cdcd.org/wpcontent/uploads/2016/02/LivingWage_Report_CDCD.pdf

Malizia, E. E., \& Ke, S. (1993). The Influence of Economic Diversity on Unemployment and Stability. Journal of Regional Science, 33(2), 221-235. Retrieved from https://journalsscholarsportal-info.ezproxy.lib.ryerson.ca/pdf/00224146/v33i0002/221_tioedouas.xml.

McFarland, C. (2017). Mid-Sized Cities are the Future of Cities, Here are Three Reasons Why. Meeting of the Minds. Retrieved from https://meetingoftheminds.org/mid-sized-cities-future-cities-threereasons-23946.

Mercer. (2018). Vienna Tops Mercer's $20^{\text {th }}$ Quality of Living Ranking. New York, US. Retrieved from https://www.mercer.com/newsroom/2018-quality-of-living-survey.html.

Milroy, B. M., and Wallace, M. (2002). Ethno-racial Diversity and Planning Practices in the Greater Toronto Area. Toronto: Centre for Excellence for Research in Immigration and Settlement, University of Toronto, 27.

Mitchell, J. (2018). After years of decline, crime rate inches up in Durham Region, stats show. Oshawa This Week. Retrieved from https://www.durhamregion.com/news-story/8976332-after-yearsof-decline-crime-rate-inches-up-in-durham-region-stats-show/.

Monofali, A. H. (1993). The Effects of Taxes and Public Infrastructure on Regional Economic Development. Texas A\&M University. Retrieved from https://search-proquestcom.ezproxy.lib.ryerson.ca/docview/304471007/A92CB811A7E141E1PQ/1?accountid=13631

Moretti, E. (2004). Estimating the social return to higher education: evidence from longitudinal and repeated cross-sectional data, Journal of Econometric, 121, 1-2, 
Oguztimur, S., \& Akturan, U. (2015). Synthesis of City Branding Literature (1988-2014) as a Research Domain. International Journal of Tourism Research Int. J. Tourism Res., 18, 357-372. doi:10.1002/jtr.2054

Onkar, P., Dhote, K. K., \& Sharma, A. (2008). Exploring the Concept of Urban Renewal in the Indian Context. ITPI Journal, 5(2), 42-46. Retrieved from https://www.researchgate.net/publication/266054840_EXPLORING_THE_CONCEPT_OF_URBAN _RENEWAL_IN_THE_INDIAN_CONTEXT.

Places to Grow Act (2017). Ontario, Canada.

Qadeer, M. A. (2016). Multicultural cities: Toronto, New York, and Los Angeles. Toronto: University of Toronto Press.

Robinson, M. (2018). Communications Strategy 2018-2021. Corporate Services Committee. Retrieved from http://app.oshawa.ca/agendas/corporate_services/2018/05-28/report_corp-18-29.pdf

Rogerson, R. (1999). Quality of Life and City Competitiveness. Urban Studies, 36, 969-985. Retrieved from https://www.researchgate.net/publication/265240251_Quality_of_Life_and_City_Competitiven ess.

Sack, R. (1988) The consumer's world: place as context, Annals of the Association of American Geographers, 78, pp. 642-664.

Shapiro, R. J., Hassett, K. A., and Arnold, F. S., (2002), Conserving Energy and Preserving the Environment: The Role of Public Transit, APTA (www.apa.com).

Statistics Canada. (2017). Ontario, Canada. Census Profile. 2016 Census. Statistics Canada Catalogue no. 98-316-X2016001. Ottawa. Released November 29, 2017. https://www12.statcan.gc.ca/census-recensement/2016/dp-pd/prof/index.cfm?Lang=E

Statistics Canada. (2017b). Oshawa, CY, Ontario and Durham, RM, Ontario. Census Profile. 2016 Census. Statistics Canada Catalogue no. 98-316-X2016001. Ottawa. Released November 29, 2017. Retrieved from: https://www12.statcan.gc.ca/census-recensement/2016/dp$\mathrm{pd} /$ prof/index.cfm?Lang=E

Statistics Canada. (2017). Focus on Geography Series, 2016 Census. Statistics Canada Catalogue no. 98404-X2016001. Ottawa, Ontario. Data products, 2016 Census.

TechEdge. (2013). Ontario Technology Survey 2012/13. Retrieved from http://www.techedge.ca/content.php?doc $=216$.

Transportation Tomorrow Survey. (2018). TTS 2016 Regional Municipality of Durham. Malatest. Retrieved from http://dmg.utoronto.ca/pdf/tts/2016/2016TTS_Summaries_Durham_Wards.pdf

United Nations. (n.d.). What is Good Governance. Economic and Social Commission for Asia and the Pacific. Retrieved from https://www.unescap.org/sites/default/files/good-governance.pdf. 
Wener, R. E., and Evans, G. W., (2007), "A Morning Stroll: Levels of Physical Activity in Car and Mass Transit Commuting," Environment and Behavior, Vol. 39, No. 1, 62-74 (http://eab.sagepub.com/cgi/content/abstract/39/1/62).

Widner, R. R. (1986). Physical Renewal of the Industrial City. ANNALS, AAPSS,488. Retrieved from https://journals-sagepub-com.ezproxy.lib.ryerson.ca/doi/pdf/10.1177/0002716286488001004.

White, R. (2016). Urban Renewal Revisited: Toronto, 1950 to 1970. The Canadian Historical Review,97(1), 1-33. Retrieved from https://muse-jhuedu.ezproxy.lib.ryerson.ca/article/612814/pdf.

Williams, A. and Jobse, P. (1990) Economic and quality of life considerations in urban-rural migration, Journal of Rural Studies, 6, pp. 187-194. 